\title{
Analysis of Fuel Properties on Combustion Characteristics in a Narrow-throat Pre-chamber Engine
}

\author{
Ponnya Hlaing, Manuel Echeverri Marquez, Paula Burgos \\ King Abdullah University of Science and Technology \\ Emre Cenker \\ Saudi Aramco \\ Moez Ben Houidi, Bengt Johansson \\ King Abdullah University of Science and Technology
}

\begin{abstract}
In this study, the authors investigated the effect of fuel properties on the combustion characteristics by employing methane, methanol, ethanol, and primary reference fuels (PRFs) as the main chamber fuel while using methane for the pre-chamber. Global excess air ratios $(\lambda)$ from 1.6 to lean limit were tested, while $13 \%$ of total fuel energy supplied to the engine was delivered via the pre-chamber. The gaseous methane was injected into the pre-chamber at the gas exchange top-dead-center (TDC). Port fuel injection was tested with both open and closed inlet valves. The pre-chamber assembly was designed to fit into the diesel injector pocket of the base engine, which resulted in a narrow throat diameter of $3.3 \mathrm{~mm}$. The combustion stability limit was set at $5 \%$ of the coefficient of variation of gross IMEP, and the knock intensity limit was set at 10 bar. GT-Power software was used to estimate the composition of pre-chamber species and was used in heat release analysis of the two chambers. It was found that the rich limit was controlled by engine knock. Hence a higher reactivity fuel (lower octane) had to be operated leaner. However, with the increasing reactivity, the lean limit was also extended, while the peak efficiency was also obtained with a leaner mixture. With PRF 90, the lean limit was at global- $\lambda=$ 3.0 , while the limit was 2.3 with methane. The alcohol fuels exhibited a different behavior from the methane and the PRFs. Ethanol has the same lean limit as PRF100, but methanol could be operated up to global- $\lambda=3.2$. The pre-chamber combustion did not change much with the different fuels in the main chamber, so the combustion stability trends must be related to the transition from burning jets to ignition of the main chamber charge and its subsequent combustion.
\end{abstract}

\section{Introduction}

The pre-chamber combustion (PCC) concept is a promising technology that can achieve higher gross indicated efficiencies and low NOx emission through lean combustion [1,2,3]. Studies in recent years suggest that the concept can suppress NOx emissions to single-digit ppm values while reducing specific fuel consumption [4]. In the PCC concept, the pre-chamber is equipped with a spark plug that initiates the combustion process. Two distinct variants of PCC concepts are found, depending on whether the pre-chamber is supplied with auxiliary fuel or not. The un-fueled pre-chamber is known as the passive pre-chamber concept. For the passive type, several products are available in the market as pre-chamber spark plugs typically used in stationary power generation and CNG engines. The passive concept promotes combustion stability and reduces combustion durations. However, no considerable lean limit

Page 1 of 22 extension over the typical SI operation is observed with the passive pre-chamber concepts [1]. The current research effort is focused on the active pre-chamber where auxiliary fuel is added into the prechamber. The active pre-chamber concepts are found to enhance the combustion stability and extend the lean limit to ultra-lean conditions $(\lambda>2.0)[5,6,7]$.

The pre-chamber typically has a small volume, which communicates with the engine cylinder or the main chamber via a series of nozzle holes. Triggering the spark plug causes the air-fuel mixture inside the pre-chamber to burn, which raises the pre-chamber pressure. This pressure buildup pushes the burning content of the pre-chamber into the main chamber as pre-chamber jets. These jets serve as multiple sources of ignition sites for consuming the main chamber contents efficiently. Gussak et al. $[8,9,10]$ indicated a pre-chamber volume should be within $2-3 \%$ of the engine clearance volume, and the ratio of total nozzle opening area of the pre-chamber to the prechamber volume should be maintained between $0.03-0.04 \mathrm{~cm}^{2} / \mathrm{cm}^{3}$ to provide an optimum trade-off between engine efficiency and emission formations. Later, Shah et al. [11] further confirmed Gussak's finding on pre-chamber geometrical parameters.

The pre-chamber employed in this study is designed according to the volume and nozzle opening area recommended by Gussak. The pre-chamber is designed to replace the diesel injector of a conventional heavy-duty diesel engine without any cylinder head modifications. Due to this design constraint, the pre-chamber includes a narrow throat with a diameter of $3.3 \mathrm{~mm}$. The dimensions of the pre-chamber are shown in Figure 1. From previous CFD studies in CONVERGE, the pressure buildup during the prechamber combustion is governed primarily by the throat diameter [12]. Accordingly, the rate of heat release in the pre-chamber is also more intense with the narrow-throat pre-chamber geometry.

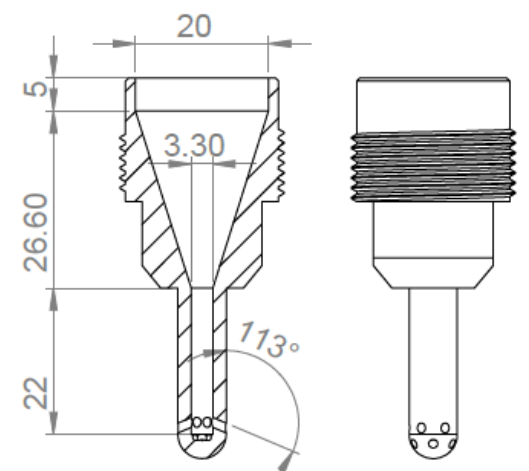

Figure 1 - Cross-section view of the pre-chamber (Dimensions are in mm) 
In our previous studies, global- $\lambda$ between 1.6 and lean limit were explored with methane injection in both pre-chamber and main chamber $[13,14]$. The amount of pre-chamber fueling was varied to examine the effect of fuel enrichment in the pre-chamber. Across all the operating conditions, the pre-chamber pressure buildup typically reached around 40-45 bar. At similar operating conditions, the turbulent jet igniter designed by MAHLE resulted in around 20 bar [15], close to the values that Shah et al. [11] observed in their 2015 paper. Vedula et al. [16], in their 2017 study, also showed similar values of the pressure difference between the two chambers. The pressure buildup in the pre-chamber provides the driving force required for the pre-chamber jets to penetrate the main chamber. In 2019, da Costa et al. [17] tested various pre-chamber geometries with different nozzle hole configurations. The experiments were conducted with gasoline (RON 92), and the combustion stability limit (CoV of IMEPg 5\%) is exceeded at global- $\lambda 2.2$. In contrast, the narrow-throat pre-chamber geometry can maintain $\mathrm{CoV}$ of IMEPg $<4 \%$ at global- $\lambda 2.3$ even when operated with methane, a less reactive fuel. In previous experiments with ethanol [13,14], the lean limit was even extended to global- $\lambda$ 2.6.

To further examine the performance of the narrow-throat prechamber, six different fuels are tested as the main chamber fuel in this study. Methane and three primary reference fuels (PRF100, PRF95, and PRF90), which are mixtures of iso-octane and nheptane, were tested to investigate the effect of octane number. Each of these four fuels has the same research octane number (RON) and motor octane number $(\mathrm{MON})$, so the sensitivity $(\mathrm{S}=\mathrm{RON}-\mathrm{MON})$ is zero. Since the difference between the octane number of methane and PRF100 is significant, methanol and ethanol, which have RON of 106 and 107, respectively [18], are tested to serve as an intermediate step in octane number. However, the MON of methanol and ethanol are 92 and 89, respectively, resulting in fuel sensitivities of 14 and 18. Hence, the second part of the study focuses on observing the effects of fuel sensitivity in PCC, while the first section is dedicated to understanding the effect of octane number.

In 2012, Attard and Blaxill [7] modified a commercially available liquid fuel injector and employed it as a pre-chamber fuel injector. A slight reduction in indicated net thermal efficiency was observed

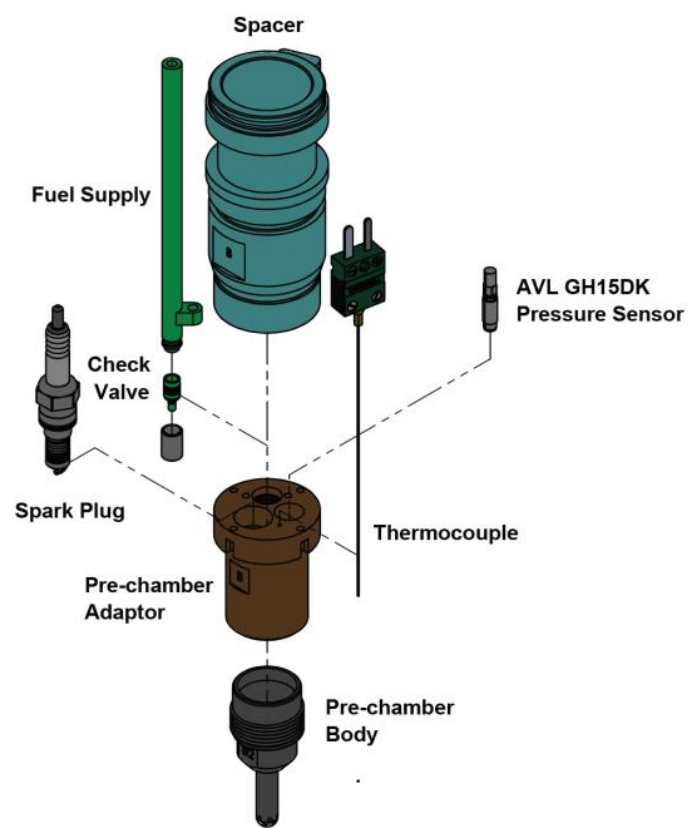

compared to the gaseous fuel injection into the pre-chamber. The researchers indicated that the mixture preparation in the prechamber was rather poor due to poor atomization of fuel detected from injector bench testing. Hence, to avoid potential complexities associated with liquid fuel injection in the pre-chamber, gaseous methane was employed as the pre-chamber fuel in all the experiments. The lean limit extension, pollutant formations, and engine performance results are presented for each of the main chamber fuels. GT-Power simulations were performed for all the data-point to estimate the composition of the pre-chamber and main chamber charge at each crank interval. The results were incorporated into heat release analysis to express the pre-chamber and the main chamber heat release rates separately. The heat release rate profiles are examined to understand the main chamber combustion processes with different fuels.

\section{Pre-chamber Design}

The pre-chamber geometrical information is tabulated in Table 1. Since the pre-chamber nozzle tip is narrow, the desired nozzle opening area cannot be distributed in a single plane. Therefore, two rows of nozzles, each containing six holes, are drilled at the prechamber tip, as shown in Figure 1. The two nozzle rows are arranged with a 30 degrees polar offset angle from the pre-chamber's longitudinal axis to avoid the nozzle holes overlapping. The two rows of pre-chamber nozzles are separated by a vertical offset height of $4 \mathrm{~mm}$ along the principal axis of the pre-chamber.

The whole assembly of the pre-chamber comprises three main parts, namely the pre-chamber body, the adaptor, and the spacer. The prechamber body, where the combustion occurs, is secured into the adaptor, which houses the spark plug, the piezoelectric pressure sensor, the thermocouple, and the check valve (The Lee Company 558 Series). The whole assembly is secured inside the diesel injector pocket of the engine by employing a clamp on top of the enclosure. The pre-chamber parts are depicted in Figure 2 (a), while Figure 2 (b) illustrates how the assembly is fitted inside the diesel injector pocket. Additional details on the pre-chamber design and material selection were provided in our previous publications $[13,19]$.

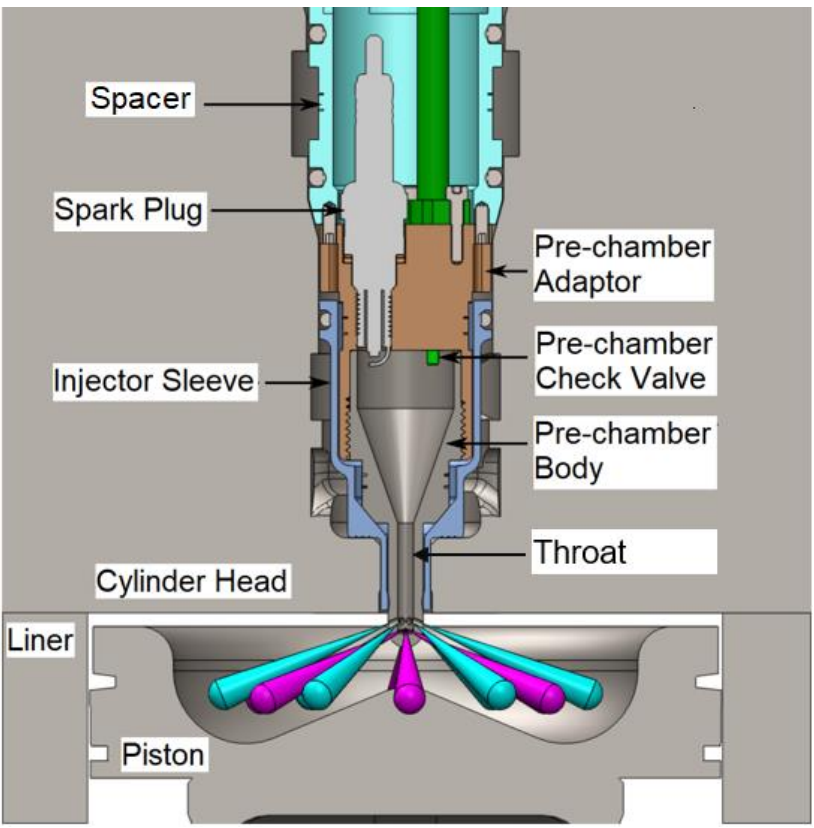

Figure 2 - Pre-chamber assembly: (a) Exploded view showing pre-chamber components, and (b) Cross-section view of the engine cylinder head 
Table 1 - Dimensions of the pre-chamber

\begin{tabular}{|l|l|l|}
\hline Parameter & Value & Unit \\
\hline Pre-chamber Volume & 5.07 & {$[\mathrm{cc}]$} \\
\hline Pre-chamber Vol./Clearance Vol. & 2.5 & {$[\%]$} \\
\hline Number of Nozzles & 12 & {$[-]$} \\
\hline Nozzle Diameter & 1.40 & {$[\mathrm{~mm}]$} \\
\hline Nozzle Area/Pre-chamber Volume & 0.035 & {$\left[\mathrm{~cm}^{-1}\right]$} \\
\hline Nozzle Included Angle & 134 & {$[\mathrm{deg}]$} \\
\hline Throat Diameter & 3.30 & {$[\mathrm{~mm}]$} \\
\hline Throat Length & 22 & {$[\mathrm{~mm}]$} \\
\hline
\end{tabular}

\section{Experimental Engine Setup}

\section{Engine Specifications}

The engine specifications are tabulated in Table 2. The singlecylinder research engine used in this study was converted from a multi-cylinder heavy-duty diesel engine. The base engine has six cylinders, which are arranged in an in-line configuration. Only one cylinder of the six units is operated, with the remaining cylinders are de-activated by removing the intake and exhaust valves. The original piston was replaced with a modified piston, which has a geometrical compression ratio of 11.5 , to reduce the knock propensity of the engine. The piston shape is $\omega$ with a bowl-in-piston design. The displacement volume of the cylinder is $2.1 \mathrm{~L}$.

Table 2 - Experimental engine specifications

\begin{tabular}{|l|l|l|}
\hline Engine Model & \multicolumn{2}{|l|}{ Volvo D13C500 } \\
\hline Control System & \multicolumn{2}{|l|}{ NI LabVIEW } \\
\hline Piston Shape & \multicolumn{2}{|l|}{ Bowl-in-piston } \\
\hline Valve Mechanism & \multicolumn{2}{|l|}{ Single Overhead Cam } \\
\hline Number of Valves & 2-Intake 2-Exhaust \\
\hline Bore & 131 & {$[\mathrm{~mm}]$} \\
\hline Stroke & 158 & {$[\mathrm{~mm}]$} \\
\hline Connecting Rod Length & 255 & {$[\mathrm{~mm}]$} \\
\hline Compression Ratio & 11.5 & {$[-]$} \\
\hline Displacement & 2.1 & {$[\mathrm{~L}]$} \\
\hline Intake Valve Timing & $\begin{array}{l}\text { Open } \\
\text { Close }\end{array}$ & $\begin{array}{l}-330 \text { CAD aTDC } \\
-170 \text { CAD aTDC }\end{array}$ \\
\hline \multirow{2}{*}{ Exhaust Valve Timing } & $\begin{array}{l}\text { Open } \\
\text { Close }\end{array}$ & $\begin{array}{l}180 \text { CAD aTDC } \\
\text {-340 CAD aTDC }\end{array}$ \\
\hline
\end{tabular}

\section{Control and Data-acquisition System}

The engine control and data-acquisition were accomplished by the real-time embedded control system, based on NI-LabVIEW software. The CompactRIO (CRio-9038), equipped with C-Series modules to perform dedicated functions, transmits user commands, and collect data from the engine instruments. A host PC was used to monitor and to communicate user commands to the CRio. A Horiba MEXA-1700 emission analyzer was used to measure the concentration of exhaust gas species.

The engine was motored by an $\mathrm{ABB}$ motor drive, which also performed the dynamometer function when the engine is producing positive work. The motor-drive software kept the engine speed at the desired constant value. The engine cylinder was fitted with a piezoelectric pressure sensor (AVL GH15DK) to measure the incylinder pressure. Another AVL GH15DK pressure sensor was used Page 3 of 22 to assess the evolution of pressure inside the pre-chamber. Piezoresistive pressure sensors (AVL LPD12A) were installed in the intake and exhaust manifold.

A crank encoder with $0.2 \mathrm{CAD}$ resolution was used to synchronize the pressure sensor measurements and the fuel injection signals. In addition, the test-cell was fitted with K-type thermocouples and average pressure sensors (WIKA A10) to monitor the sub-systems such as the cooling water system, lubricating oil system, air intake, and exhaust systems.

\section{Pre-chamber Fuel Injection System - Gaseous}

The lab gaseous fuel line branched into two, one for the pre-chamber fueling and another for the main chamber fuel delivery (if needed). The pre-chamber fuel supply line was fitted with a damping vessel to smoothen out pressure pulsations. A Brooks SLA5850 mass flow controller was installed after the damping vessel to control the prechamber fuel flow rate. A CleanAirPower SP-021 solenoid valve was installed after the mass flow controller to determine the crank angle timing of the fuel introduced into the pre-chamber. A K-type thermocouple and an AVL LPD12A piezoresistive pressure sensor were installed in the fuel supply line after the solenoid valve to measure the temperature and the pressure of the pre-chamber fuel.

It is required to mention here that the solenoid valve action does not dictate the fuel injection timing into the pre-chamber. The fuel injection into the pre-chamber is achieved when the fuel line pressure rises above the pre-chamber pressure. Otherwise, the check valve prevents the fuel from flowing back into the pre-chamber. Moreover, the length of the fuel line between the solenoid valve and the pre-chamber is considerable, which is around 1.7 meters. For the solenoid valve opening timing at $-360 \mathrm{CAD}$ aTDC and opening duration of 6.5 milliseconds, the fuel line pressure stays above the pre-chamber pressure well into the compression stroke.

\section{Main Chamber Fuel Injection System - Gaseous}

The engine was fitted with a modified intake manifold with two pockets to install the port-fuel injectors. Bosch NGI2 injectors were employed for gaseous fuel injection into the air intake. As in the pre-chamber fuel line, the main chamber gaseous fuel line enters a damping vessel to diminish pressure oscillations. The outlet of the damping vessel connects to the two injectors via a mass flow meter to measure the fuel flow rate. The mass flow meter is manufactured by Brooks, and the model is SLA5853. The original model is a mass flow controller but is configured as a flow meter.

\section{Main Chamber Fuel Injection System - Liquid}

For liquid fuel injections, the Bosch NGI-2 injectors were replaced with the Bosh EV14 injectors. For the load range of interest in this study, the single injector operation was sufficient, and hence the injector closer to the engine is used consistently throughout the experiments. A low pressure automotive common rail fed the liquid fuel to the port fuel injectors. Fuel from the liquid fuel tank was pumped to the common rail by a submerged fuel pump. Fuel consumption was measure by a mass balance (Radwag PM10.C32). A Coriolis mass flowmeter (Brooks QMBM4) was installed downstream of the fuel pump to check against the fuel flow measured by the balance. The balance and Coriolis flowmeter measurements were within $2 \%$ variation, and the flowmeter readings were used in the data analysis since the response of the mass flow 
meter is faster than the fuel balance. The common rail is also fitted with a WIKA A10 pressure sensor to measure the fuel pressure.

Two schematic diagrams of the experimental setup are presented in Figure 3 (a) and (b) - the first with liquid fuel injection into the main chamber and the latter with gaseous fuel injection. Individual components in the schematic diagrams are explained in the caption.
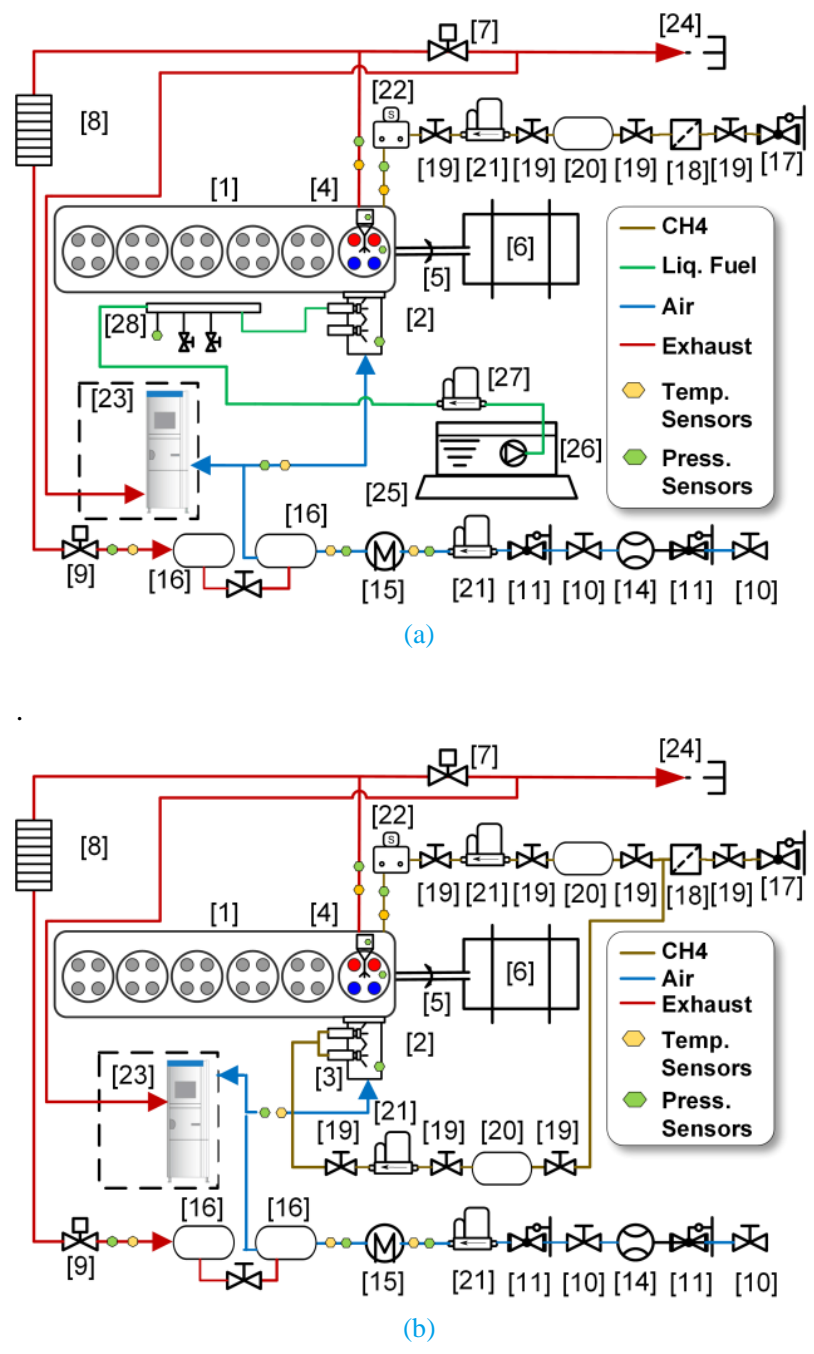

Figure 3 - Schematic diagram of the experimental setup - (a) Liquid fuel injection into the main chamber, and (b) Gaseous fuel injection into the main chamber (1. Engine, 2. Intake manifold, 3. Port fuel injectors, 4. Prechamber, 5. Cardan shaft, 6. Dynamometer, 7. Back pressure valve, 8. EGR Cooler, 9. EGR valve, 10. Main air valve, 11. Pressure regulator, 12. Control air valve, 13. Intake throttle valve, 14. Air flowmeter, 15. Air heater, 16. Mixing Tank, 17. Main gas fuel valve, 18. Gas fuel filter, 19. Valve, 20. Pressure damping vessel, 21. Mass flow controllers/meters, 22. Pre-chamber injector, 23. Horiba exhaust analyzer, 24. Vent to the atmosphere, 25. Mass balance, 26. Fuel tank and submerged pump assembly, and 27. Coriolis mass flow meter, and 28. Low-pressure common rail.)

\section{Operating Conditions and Methodology}

\section{Experimental Conditions}

For the first part of the study, methane ( $99.5 \%$ purity) and the PRF mixtures were injected into the air intake to examine the effect of octane number on main chamber combustion. The fuel sensitivity effect on the main chamber combustion was tested using methanol

Page 4 of 22 and ethanol in the second section. Hence, the results and discussion section will be divided into two major sub-sections accordingly.

The research engine was modified from the base diesel engine, and therefore, it was not designed for fuel injection through the intake manifold. The intake port geometry is not designed to impart swirl to the intake charge motion since the base engine is supposed to be operated with a quiescent combustion chamber. On the other hand, the test engine is also fitted with an in-house designed air intake manifold, onto which the port fuel injectors are installed. The spray from the PFI could not be directed onto the intake valves as in a conventional SI engine due to the geometry limitation of the intake passage. In our previous publications [13,14], the liquid fuel application suffered from poor combustion efficiency. The fuel was introduced into the air intake during the gas exchange period (start of injection at -360 CAD aTDC) in those experiments. In this study, two main chamber fuel injection timings were tested for the liquid fuel cases: at -360 CAD aTDC and -150 CAD aTDC. The prior will be termed open valve injection since the fuel is injected into the intake when the inlet valves are open. The latter is termed closed valve injection, as the intake valves are closed when the fuel is introduced. Therefore, the fuel stays inside the intake passage until the intake valve opens again in the next cycle.

This fuel injection method is considered to promote the vaporization of the injected fuel since the fuel could take up the heat from hot cylinder environments for a longer duration of time. The closed valve fuel injection strategy shows significant improvement in fuel utilization for all the liquid fuels studied. Hence, for these fuels, only the results with closed valve injection timings will be discussed to achieve a fair comparison with methane. For gaseous methane injection into the main chamber, the fuel timing was kept at -360 CAD aTDC. The same timing was adopted for the solenoid valve in the pre-chamber fuel supply line. A brief discussion on the fuel timing effects will be presented in the subsequent section, using cases with ethanol since the trends are similar for all the liquid fuels.

In all the experiments, the fraction of fuel energy supplied to the prechamber, represented by the term pre-chamber fuel mean effective pressure (FuelMEP) ratio (PCFR), was kept constant at $13 \%$ as the study aims at unraveling the characteristics of main chamber combustion with different fuels. This setting has shown the highest extension of the lean limit in the previous studies [19]. On the other hand, parallel studies in a similar research engine with optical access reported that the main chamber combustion characteristics are largely insensitive to the PCFR [20,21]. Hence, keeping a constant PCFR is deemed suitable for isolating the effect of fuel properties on the main chamber combustion. A brief discussion on the mixture formation inside the pre-chamber is included in the results and discussion section.

The FuelMEP and PCFR are defined as follows

$$
\text { FuelMEP } P_{P C, M C}=\frac{\text { mass of } \text { fuel }_{P C, M C} \times \text { LHV of Fuel }}{\text { Engine Displacement Volume }}
$$

$$
\text { PCFR }=\frac{\text { FuelMEP } P_{P C}}{\text { FuelMEP } P_{P C}+\text { FuelMEP } P_{M C}} \times 100
$$

From equations (1) and (2), the engine displacement volume will cancel out in the PCFR definition. Hence, the FuelMEP ratio is equivalent to the ratio of fuel energy of the pre-chamber over the 
total fuel energy supplied to the engine. The combustion stability limit is assumed at 5\% coefficient of variation of gross IMEP (CoV of IMEPg). The knock intensity is calculated from bandpass filtering the main chamber pressure signal [22]. The signal is rectified, and the maximum amplitude of the signal is identified for each engine cycle. The knock intensity calculated in this manner is also termed the maximum amplitude of pressure oscillations (MAPO). The averaged values of MAPO for 500 cycles are reported in the paper as knock intensity. The frequency bands for the bandpass filter are taken at 4 to $17.5 \mathrm{kHz}$, based on the power spectral density analysis of knocking cycles. Since the data acquisition frequency is at 36 $\mathrm{kHz}$, the higher frequency band must be less than $18 \mathrm{kHz}$ to fulfill the Nyquist criterion. Therefore, $17.5 \mathrm{kHz}$ is chosen as the high band frequency. Since only low loads conditions are investigated, the knock limit was set at 10 bar to study the high knock conditions.

The engine speed was kept constant at $1200 \mathrm{rpm}$, and the intake pressure was fixed at 1.5 bar. The back-pressure valve of the exhaust line was operated to achieve a higher exhaust pressure in the exhaust over the intake pressure by $0.2 \pm 0.05$ bar. The aim is to simulate the pressure drop caused by the turbocharger and the exhaust aftertreatment system in real engines. For each data-point, the data is recorded for 500 cycles. The experimental operating conditions are summarized in Table 3.

Table 3 - Experimental Operating Conditions

\begin{tabular}{|c|c|c|}
\hline & Units & Values \\
\hline Engine Speed & RPM & 1200 \\
\hline Coolant Temp. & ${ }^{\circ} \mathrm{C}$ & $83 \pm 5$ \\
\hline Lub. Oil Temp. & ${ }^{\circ} \mathrm{C}$ & $85 \pm 5$ \\
\hline Intake Temp. & ${ }^{\circ} \mathrm{C}$ & $30 \pm 1$ \\
\hline Intake Press. & bar & $1.5 \pm 0.05$ \\
\hline Exhaust $\Delta \mathrm{P}$ & bar & $0.2 \pm 0.05$ \\
\hline PC Fuel SOI & CAD aTDC & -360 \\
\hline MC Fuel SOI & CAD aTDC & $\begin{array}{l}-360 \text { for } \mathrm{CH}_{4} \\
-150 \text { for Liquids }\end{array}$ \\
\hline PC Fuel & \multicolumn{2}{|l|}{$\mathrm{CH}_{4}(99.5 \%)$} \\
\hline MC Fuel & \multicolumn{2}{|l|}{$\begin{array}{l}\mathrm{CH}_{4}(99.5 \%) \\
\text { PRF100 } \\
\text { PRF95 } \\
\text { PRF90 } \\
\text { Methanol }(99 \%) \\
\text { Ethanol }(96 \%)\end{array}$} \\
\hline Spark Timing & \multicolumn{2}{|l|}{ MBT } \\
\hline PC FuelMEP: Total FuelMEP & \multicolumn{2}{|l|}{$13 \%$} \\
\hline Knock Limit & \multicolumn{2}{|l|}{10 bar } \\
\hline CoV of IMEPg Limit & \multicolumn{2}{|l|}{$5 \%$} \\
\hline
\end{tabular}

Global- $\lambda$ sweeps were performed for all six fuels, starting from the knock limit until the lean limit, where the combustion stability limit is exceeded. In the case of methane and the alcohols, the richest global- $\lambda$ explored was 1.6 since the interest of the study is in lean conditions. These fuels were resistant to knock, and the knock limit of 10 bar was not reached at global- $\lambda$ 1.6. At each operating condition, the spark timing is adjusted to achieve the maximum brake torque (MBT) of the engine. As the global- $\lambda$ became leaner, for all the fuels, the spark timings were required to be advanced to achieve MBT.

Methanol and ethanol were resistant to knock, and the lean capability of these fuels was also high. Therefore, a wider global- $\lambda$ range can be investigated for these two fuels. The data matrix is summarized in Table 4, along with the octane ratings of the fuels, taken from the literature [18].

Page 5 of 22
Table 4 - Data Matrix

\begin{tabular}{|c|c|c|c|c|c|c|}
\hline & Methane & PRF100 & PRF95 & PRF90 & Methanol & Ethanol \\
\hline RON & 120 & 100 & 95 & 90 & 106 & 107 \\
\hline MON & 120 & 100 & 95 & 90 & 92 & 89 \\
\hline \multicolumn{7}{|c|}{ Global- $\lambda$} \\
\hline 1.6 & o & & & & o & o \\
\hline 1.8 & o & & & & o & o \\
\hline 1.9 & o & $\wedge$ & & & o & o \\
\hline 2.0 & $\mathrm{o}$ & $\mathrm{o}$ & $\wedge$ & & $\mathrm{o}$ & $\mathrm{o}$ \\
\hline 2.1 & 0 & o & o & & 0 & 0 \\
\hline 2.2 & o & o & o & $\wedge$ & o & o \\
\hline 2.4 & $\mathrm{v}$ & o & o & o & o & o \\
\hline 2.6 & & o & o & 0 & o & o \\
\hline 2.8 & & $\mathrm{o}$ & $\mathrm{o}$ & $\mathrm{o}$ & $\mathrm{o}$ & $\mathrm{o}$ \\
\hline 3.0 & & $\mathrm{~V}$ & 0 & o & $\mathrm{o}$ & $\mathrm{V}$ \\
\hline 3.1 & & & $\mathrm{~V}$ & o & o & \\
\hline 3.2 & & & & $\mathrm{v}$ & o & \\
\hline 3.4 & & & & & $\mathrm{v}$ & \\
\hline \multicolumn{7}{|c|}{$\begin{array}{l}\wedge \text { - Knock limit } \\
\mathrm{o}-\text { Stable operating condition } \\
\vee \text { - Lean limit }\end{array}$} \\
\hline
\end{tabular}

\section{Heat Release Analysis}

The heat release calculations are performed separately for the prechamber and the main chamber based on the method proposed by Duong et al. [23]. The method is based on the first law analysis and uses the isentropic flow equation to estimate the mass transfer between the pre-chamber and the main chamber [18]. The equation is shown below in equation (3). The positive direction of mass transfer is assumed when the pre-chamber is discharging mass into the main chamber and vice versa. The terms in all the equations in this section are explained in the abbreviation section.

$$
d m=\frac{C_{d} A_{T} P_{P C}}{\sqrt{R T_{P C}}}\left(\frac{P_{M C}}{P_{P C}}\right)^{\frac{1}{\gamma}}\left[\frac{2 \gamma}{\gamma-1}\left(1-\left(\frac{P_{M C}}{P_{P C}}\right)^{\frac{\gamma-1}{\gamma}}\right)\right]^{\frac{1}{\gamma}}
$$

The expression used to calculate the main chamber rate of heat release is shown in equation (4).

$$
\frac{d Q_{M C}}{d \theta}=\frac{\gamma}{\gamma-1} P_{M C} \frac{d V_{M C}}{d \theta}+\frac{1}{\gamma-1} V_{M C} \frac{d P_{M C}}{d \theta}-h_{P C, M C} \frac{d m}{d \theta}
$$

The equation consists of (a) the rate of heat release due to pressure buildup caused by combustion, (b) the rate of heat release due to volume change due to piston movement, and (c) the rate of heat release due to enthalpy transfer to and from the pre-chamber.

The pre-chamber rate of heat release is calculated as in equation (5).

$$
\frac{d Q_{P C}}{d \theta}=\frac{1}{\gamma-1} V_{P C} \frac{d P_{P C}}{d \theta}+h_{P C, M C} \frac{d m}{d \theta}
$$

Since the pre-chamber volume is constant, the expression consists of (a) the rate of heat release due to pre-chamber pressure buildup and (b) the rate of heat release due to enthalpy transfer to and from the main chamber. Here, the CAD duration, where the pre-chamber rate of heat release analysis is performed, needs to be assessed. The pre-chamber combustion events are shown in Figure 4.

As in conventional SI combustion, the pre-chamber heat release calculation is initiated at the spark timing. The initial heat release rate is slow until the pre-chamber pressure becomes equal to the main chamber pressure. This crank angle location is termed as $\Delta P$ reversal 1 since the sign of the pressure difference between the prechamber and the main chamber becomes positive at this point 
Similarly, near the end of pre-chamber combustion, the pressure in the pre-chamber drops and becomes equalized with the main chamber at $\Delta P$ reversal 2 . However, the previous CFD results show that mass discharge from the pre-chamber into the main chamber continues until the local minimum is reached in the pre-chamber pressure [24]. Hence, the heat release rate in the pre-chamber is calculated between the spark timing and the local minimum of prechamber pressure after the $\Delta P$ reversal 2.

From equation (3), it is obvious that the estimation of the discharge coefficient is important in determining the mass transfer between the two chambers with sufficient accuracy. Moreover, the mixture composition must be known to estimate the specific heat ratio $(\gamma)$. Also, equations (4) and (5) require a proper understanding of mixture composition to estimate heat release rate with some confidence. Especially for the pre-chamber, since the volume of the chamber is small compared to the main chamber, the pre-chamber rate of heat release is found to be sensitive to species composition, which in turn is dependent on the mass transfer between the two chambers.

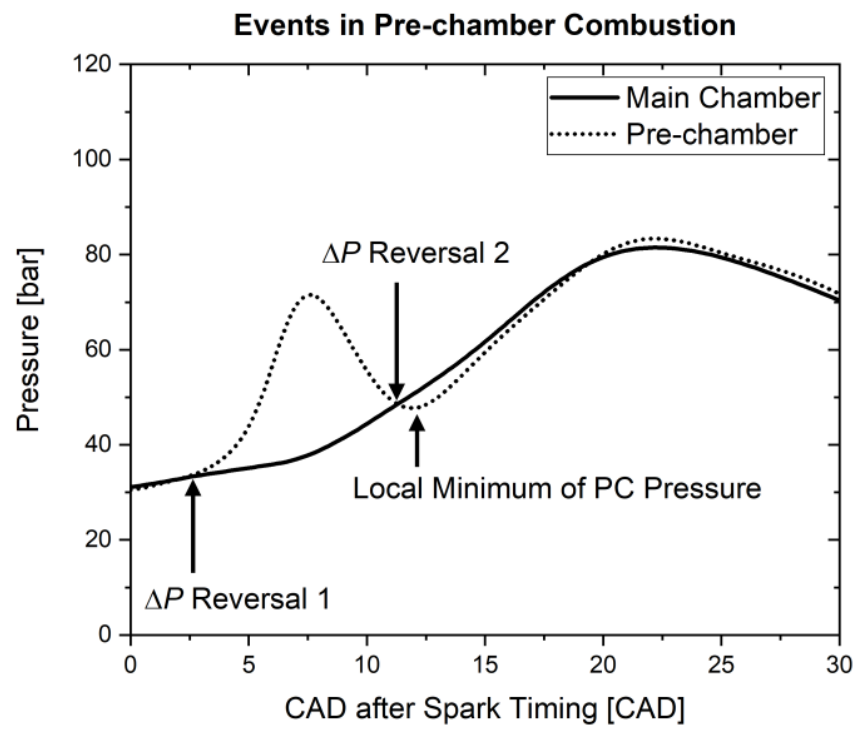

Figure 4 - Pre-chamber Combustion Events

\section{GT-Power Model}

Therefore, a GT-Power model (v2020) is built to assess the muchneeded species composition at each crank interval. The pre-chamber and main chamber are simulated using the pre-chamber template and the engine cylinder template, respectively. The pre-chamber nozzles are represented by the "Engine Pre-combustion Chamber Nozzle" object. The detailed geometry of the pre-chamber cavity is entered into the pre-chamber template using the advanced geometry features. The intake and exhaust valve lift profiles are measured from the engine and implemented into the respective valve objects. The discharge coefficient data for the valve lift is provided by the engine manufacturer. Instantaneous intake and exhaust pressure traces from the experiments are included in the three-pressureanalysis (TPA) environment objects for the intake and exhaust. The pre-chamber and the main chamber experimental pressure traces are entered into the respective templates for analysis. The intake and exhaust pipes are assumed to be adiabatic.

The pre-chamber combustion is predicted using the SI turbulent flame combustion model, which is the typical template used to simulate spark-ignited engines. The main chamber combustion process is simulated using the jet ignition combustion model. A detailed description of the jet ignition combustion model can be found in the studies undertaken by Wenig et al. [25,26]. The prechamber and main chamber templates are operated in "heat releasebased calibration (HRBC)" mode. In this mode, the pre-chamber and main chamber apparent heat release rates are calculated based on the respective experimental pressure traces. The apparent heat release rates are used in burn rate calculation in the prediction runs. The discharge coefficient of the pre-chamber nozzles is determined by matching the pre-chamber and main chamber pressure traces. The methodology was introduced in the previous work of the authors [21]. From the pre-chamber species composition, the temperature and specific heat ratio $(\gamma)$ of the pre-chamber can be calculated. Hence, the discharge coefficient and species composition of the prechamber is used in the heat release calculation.

\section{Results and Discussion}

The first part of the section presents the effect of main chamber fuel injection timings, followed by the second section, where the mixture formation process inside the pre-chamber is discussed briefly. In the third section, the effect of octane number will be presented using methane, PRF100, PRF95, and PRF90. The fourth section reports the effect of fuel sensitivities by analyzing the results with methanol and ethanol. In the last section, the rate of heat release profiles will be compared between all the fuels used in this study.

\section{Effect of Main Chamber Fuel Injection Timing}

In this section, the combustion efficiency and unburned hydrocarbon emissions are compared between the open valve and closed valve injection timing. For brevity, only the ethanol results are shown for stable operating points (CoV of IMEPg $<3 \%$ ) between global- $\lambda 1.8$ and 2.6. As shown in Figure 5 (a), the combustion efficiency is poorer with the open valve injection for all the global- $\lambda$ conditions assessed. Similarly, in Figure 5 (b), the unburned hydrocarbon emissions are higher with the open valve injection. The higher unburned hydrocarbon emission could be attributed to the poor vaporization of the fuel. Therefore, the mixture preparation is relatively compromised with the open valve injection timing, while the closed valve injection provides improved fuel utilization. Hence, only the outcomes with closed valve injections are presented in the paper for the liquid fuel results.

Page 6 of 22 


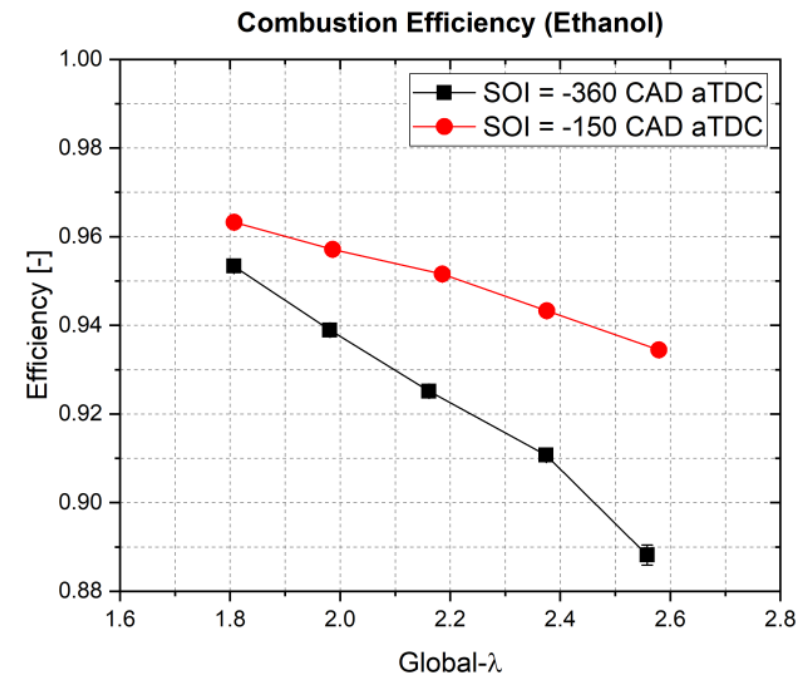

(a)

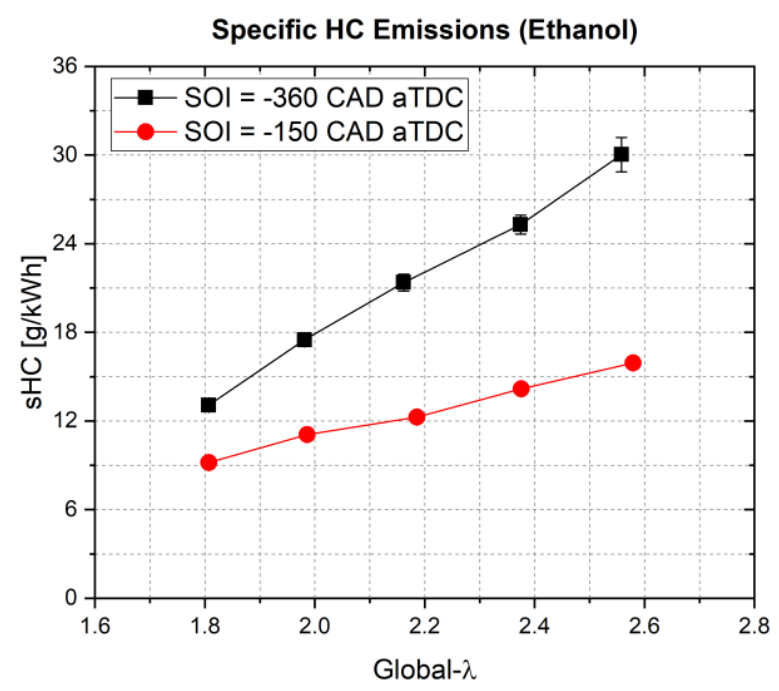

(b)

Figure 5 - Open valve injection vs. closed valve injection: (a) Combustion efficiency and (b) Specific hydrocarbon emissions

\section{Mixture Formation in Pre-chamber}

The fuel injection process into the PC is explained in Figure 6 (a), using the global- $\lambda$ 1.6 cases with methane as an example. Throughout the experiments, the PCFR was kept at $13 \%$. Even though the solenoid valve was opened at -360 CAD aTDC, a substantial pressure rise in the fuel line occurs around -340 CAD aTDC. The delay could be related to the inertia of the solenoid valve. As long as the fuel line pressure is higher than the pre-chamber pressure, fuel flows into the pre-chamber, rendering the PC- $\lambda$ to become very low between -340 and -170 CAD aTDC, where the intake valves close and compression begins in the cylinder. From this point onward, the rising piston causes lean air and fuel mixture from the main chamber to enter the pre-chamber, increasing the prechamber $\lambda$. For this case, the pre-chamber $\lambda$ reaches 0.8 , indicating fuel-rich composition in the pre-chamber.
Fuel Injection Process into PC $\left(\mathrm{CH}_{4}\right.$ : Global- $\lambda$ 1.6)

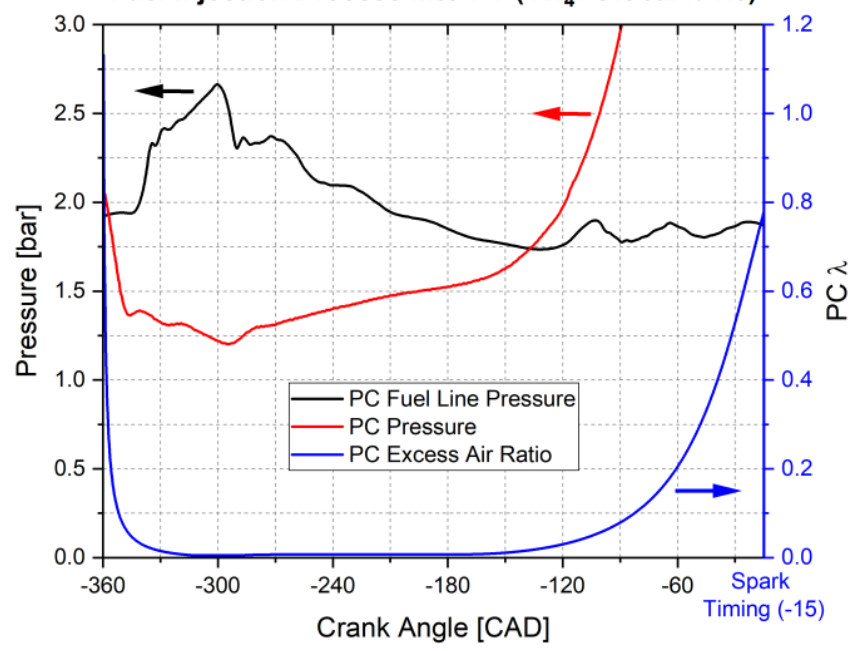

Figure 6 - Mixture formation process in the pre-chamber

\section{Effect of Octane Number of Main Chamber Fuel}

In this section, the results with methane and the three PRF fuels are analyzed to understand the effect of octane number on the prechamber combustion concept. The section is divided into three subsections, namely (a) operating characteristics, (b) knock and emissions, and (c) efficiency and gross IMEP.

\section{Operating Characteristics}

The combustion stability for methane and the PRFs is plotted in Figure 7 (a). The lean capability with methane combustion is very limited since the $\mathrm{CoV}$ of the IMEPg limit is exceeded after the global- $\lambda$ of 2.3. On the other hand, the lean limit is progressively extended to global- $\lambda$ 3.0, 3.1, and 3.2, with PRF100, PRF95, and PRF90 fuels. Hence, it is observed that operating with lower octane fuels, thereby improving the fuel reactivity, can further extend the lean limit. The finding is important since it implies that more reactive fuels can improve the lean capability or dilution tolerance of the PCC concept.

As shown in Figure 7 (b), the MBT spark timings generally show a downward trend, indicating that the spark timings need to be further advanced as the global- $\lambda$ becomes leaner. With the increasing octane number of the fuel, for a given global- $\lambda$, further advancement of spark timing is required when compared to fuels with lower octane number. At global- $\lambda$ of 2.2 and 2.4, the MBT spark timing of PRF100 and 95 are identical. This overlap of MBT spark timing is probably because of the spark timings step used in this study, which is $2 \mathrm{CAD}$. A finer spark timing step might give a clearer separation of spark timing with decreasing fuel octane number. Near the lean limit, the spark timings need to be advanced much further to sustain combustion. Regardless of spark timing advance, misfires start to occur at the lean limit, rendering the $\mathrm{CoV}$ of IMEPg to rise above $5 \%$.

In Figure 7 (c), the pre-chamber $\lambda$ at the time of spark is given for each global- $\lambda$ case for each fuel. The pre-chamber $\lambda$ values were calculated using the GT-Power model. As explained in the previous paragraph, the spark timings need to be earlier when operating the main chamber with high-octane fuels. Advancing the spark timing limits the amount of lean main chamber air-fuel mixture entering the pre-chamber during the compression stroke. Hence, for a given 
global- $\lambda$, fuels with a higher octane number result in richer prechamber $\lambda$. For each fuel, increasing the global- $\lambda$ results in a leaner main chamber charge mixing with the pre-chamber contents. However, the spark timing is also continually advance with increasing global- $\lambda$. Hence, the pre-chamber $\lambda$ trend is not monotonic. Close to the lean limit, the spark timings are much further advanced so that the pre-chamber $\lambda$ becomes rich again at these ultra-lean regions.

The pressure buildup in the pre-chamber, reported in Figure 7 (d), is sensitive to the fuel property as well as the pre-chamber $\lambda$. The fuel content in the pre-chamber just before the spark timing is a mixture of main chamber fuel and pre-chamber fuel. Hence, compared to single-fuel operation with methane, the pre-chamber charge reactivity is improved by mixing with lower octane fuel. Due to its slow flame speed, the pressure buildup in the methane case is comparatively smaller than the results with the PRF fuels. On the other hand, the PRF fuels have similar flame speeds, and the pressure buildup for these fuels appears to be highly sensitive to the pre-chamber $\lambda$. The PRF90 cases have the pre-chamber $\lambda$ close to stoichiometry, and these cases have the highest pressure buildup among the fuels studied in this paper.

As presented in Figure 7 (e), the delay between the spark timing and $10 \%$ heat release appears to be a strong function of the pressure buildup in the pre-chamber. This delay is also known as the flame development angle, and the delay increases as the mixture become leaner (higher global- $\lambda$ ). Cases with methane as the main chamber fuel show the longest delay, while PRF90 cases show the shortest delay among all the fuels tested. Hence, a shorter flame development angle can be expected by using fuels with a lower octane rating.

The duration between 10 to $90 \%$ heat release (CA10-90) is plotted in Figure 7 (f). For each fuel in this study, the combustion duration is extended monotonically as the global- $\lambda$ increases. For a given global- $\lambda$ condition, shorter durations are achieved by employing fuels with a lower octane rating. Due to its slow laminar burning velocity, methane shows the longest combustion duration among the fuels studied for a given global- $\lambda$ condition. The rate at which the combustion duration increases with increasing global $-\lambda$ is similar for all the PRF fuels. However, in the case of methane, the combustion duration increases drastically beyond global- $\lambda 2.2$ since the $\mathrm{CoV}$ of IMEPg increases rapidly beyond this point. An important observation is that the combustion durations are typically short, usually below $20 \mathrm{CAD}$ for conditions with $\mathrm{CoV}$ of IMEPg $<3 \%$. Even while avoiding high knock intensities, the PCC concept can still achieve short combustion duration at ultra-lean conditions.

\section{Knock and Indicated Specific Emissions}

The knock intensity, specific $\mathrm{NOx}, \mathrm{CO}$, and $\mathrm{HC}$ emissions are presented in this sub-section. As shown in Figure 8 (a), the lower PRF fuels show significant knock intensities, while for methane, the knock limit of 10 bar intensity is not reached at the global- $\lambda$ 1.6. From PRF100 to PRF90, the knock-limited global- $\lambda$ shifts from 1.9 to 2.2. However, the knock intensities decrease as the global- $\lambda$ becomes leaner, and the engine can operate with a wide range of global- $\lambda$ with low knock intensities beyond global- $\lambda$ 2.4. A singlecycle main chamber pressure trace with the highest knock intensity cycle is presented for the methane, and the PRF fuels are presented in Appendix A (see Figure A.1).

Figure 8 (b) shows that the specific NOx emissions values are closely tied to the global- $\lambda$ and relatively insensitive to fuel properties. For each fuel, the specific NOx emission increases when the global- $\lambda$ reduces. For methane, the specific NOx emissions exceed $1.0 \mathrm{~g} / \mathrm{kWh}$ below global $-\lambda 1.8$. Between global- $\lambda 1.9$ and 2.0 , the lower octane fuels show marginally higher specific NOx emissions than methane. Moreover, the specific NOx emissions are slightly lower for PRF95 fuel than the rest.

Olsen and Lisowski [27] indicated that the main source of NOx emissions at ultra-lean conditions could be the pre-chamber rather than the main chamber combustion. Onofrio et al. [28] experimentally demonstrated that the NOx emission at ultra-lean conditions is sensitive to spark timing. In this case, the NOx emissions of PRF95 are slightly lower due to the spark timings. The specific NOx emission results against the spark timing are presented for the PRF fuels in Appendix B (see Figure B.1). For all the fuels, beyond the global- $\lambda$ of 2.0 , the specific NOx emissions fall below $1.0 \mathrm{~g} / \mathrm{kWh}$ and maintain a stable value of around $0.5 \mathrm{~g} / \mathrm{kWh}$ until the lean limit.

The indicated specific carbon monoxide (CO) and unburned hydrocarbons (HC) emissions are presented in Figure 8 (c) and (d). The specific carbon monoxide emissions for methane are around 2$3 \mathrm{~g} / \mathrm{kWh}$ up to the global- $\lambda$ of 2.0. Beyond global- $\lambda 2.0$, the specific $\mathrm{CO}$ emission of methane rises rapidly, primarily due to poor combustion stability. A similar trend is observed for unburned hydrocarbon emissions, albeit the specific $\mathrm{HC}$ emissions rise faster than the CO. The observation indicates that a portion of the injected fuel is not broken down by the combustion process and ejected from the engine as unburned hydrocarbons. This emission is termed as methane-slip in natural gas engines.

For the PRFs, the specific $\mathrm{CO}$ and $\mathrm{HC}$ emissions have similar trends, while the $\mathrm{HC}$ emissions are marginally higher than $\mathrm{CO}$. The specific $\mathrm{CO}$ and $\mathrm{HC}$ emissions are relatively low at the knock limit, ranging around $2-3 \mathrm{~g} / \mathrm{kWh}$ in $\mathrm{CO}$ and $4-5 \mathrm{~g} / \mathrm{kWh}$ in $\mathrm{HC}$ emissions. The specific $\mathrm{CO}$ emissions rise sharper than the $\mathrm{HC}$ emissions as the global- $\lambda$ becomes leaner. The observation indicates that the $\mathrm{CO}$ to $\mathrm{CO}_{2}$ oxidations becomes less efficient at very lean conditions $(\lambda>$ 2.6) with the PRF fuels. Although the $\mathrm{CO}$ and $\mathrm{HC}$ emissions are linked to global- $\lambda$, fuels with lower octane number have lower emissions, especially in $\mathrm{HC}$ emissions at similar global- $\lambda$ conditions.

Page 8 of 22 


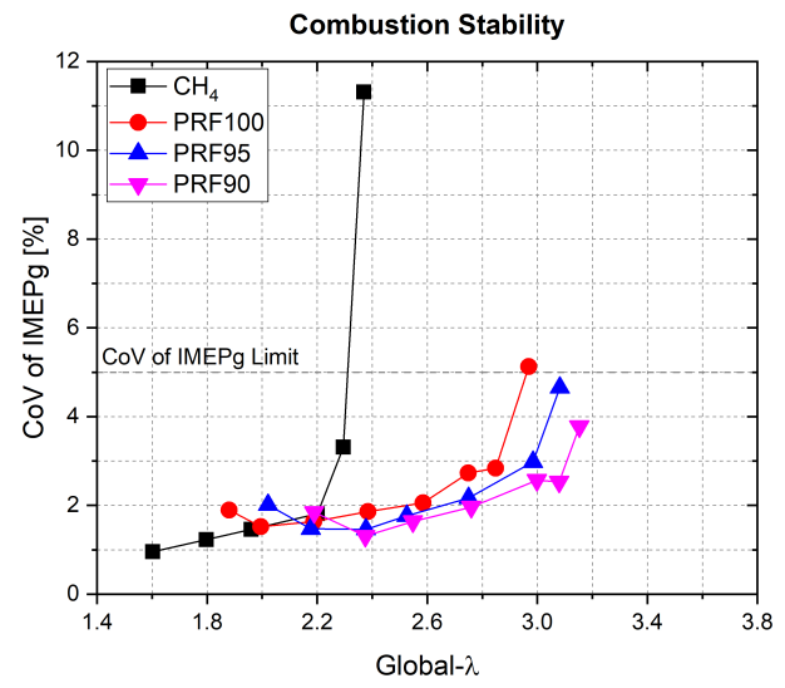

(a)

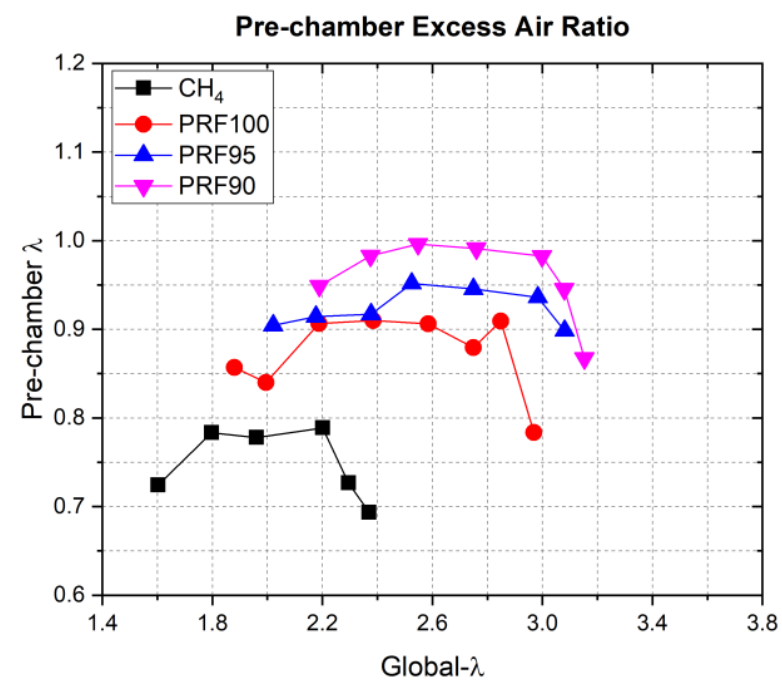

(c)

Duration between Spark Timing and $10 \%$ Heat Release

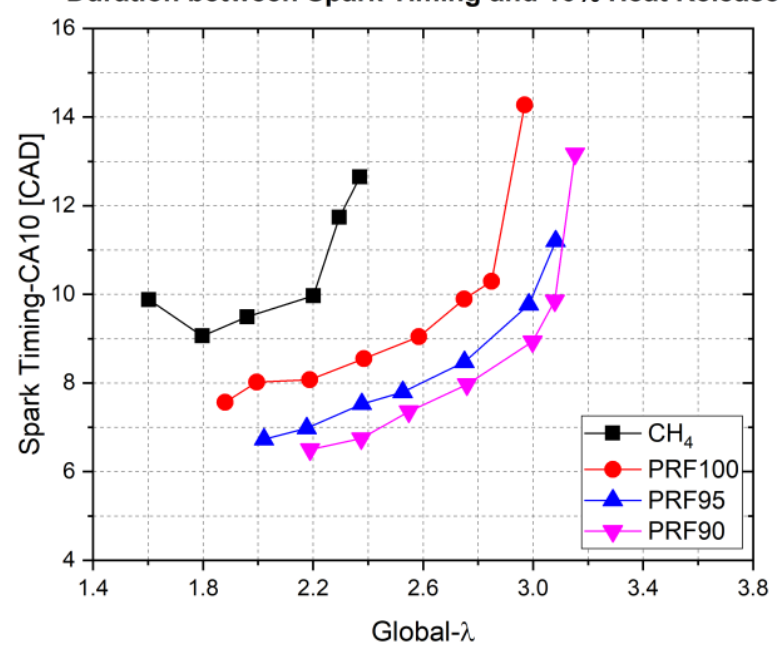

(e)

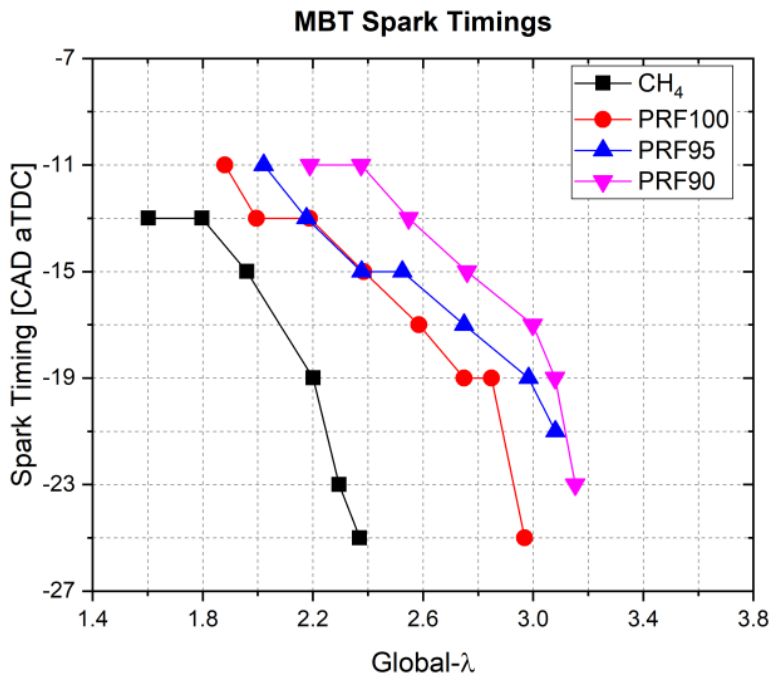

(b)

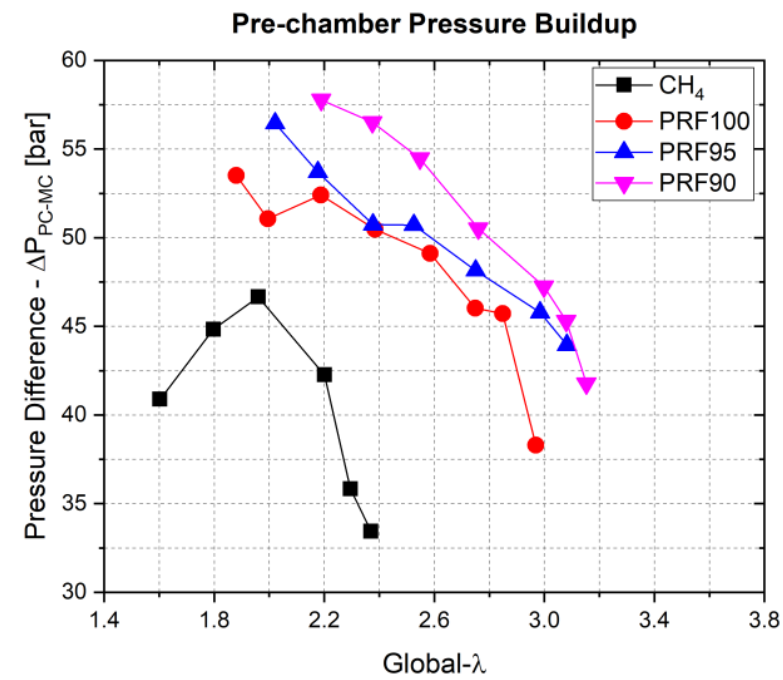

(d)

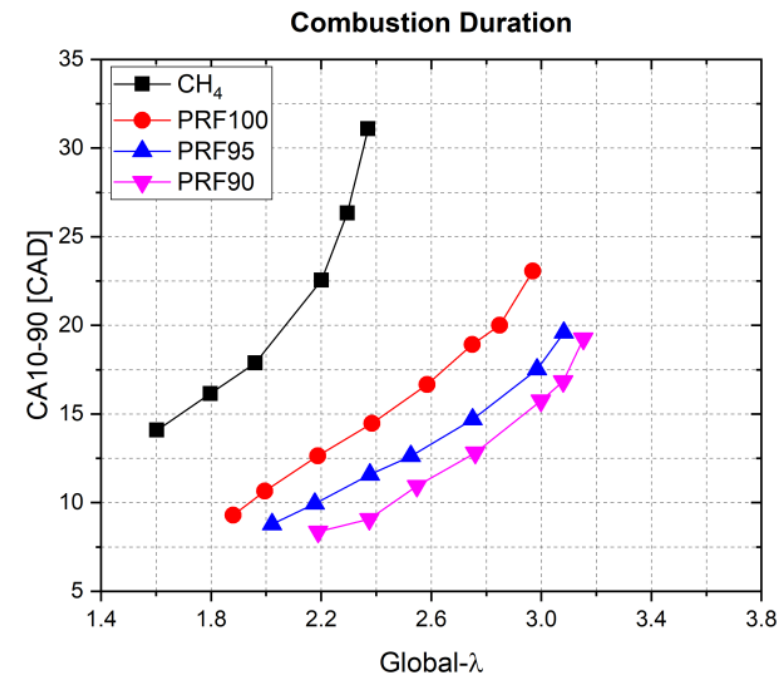

(f)

Figure 7 - Effect of octane number on operating characteristics: (a) Combustion stability, (b) MBT spark timings, (c) Pre-chamber $\lambda$, (d) Pressure buildup in the pre-chamber, (e) Duration between spark timing and 10\% heat release, and (f) Duration between $10 \%$ and $90 \%$ heat release

Page 9 of 22

$01 / 28 / 2020$ 


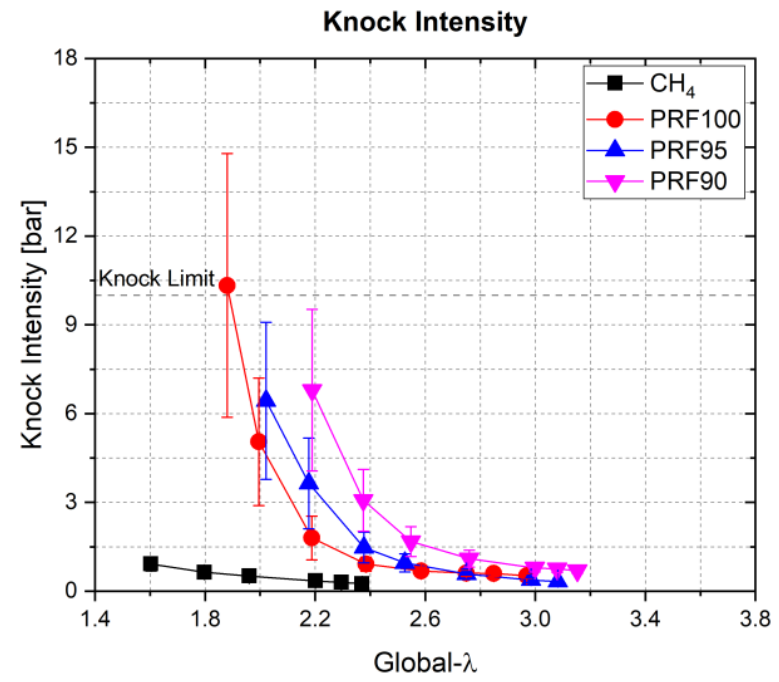

(a)

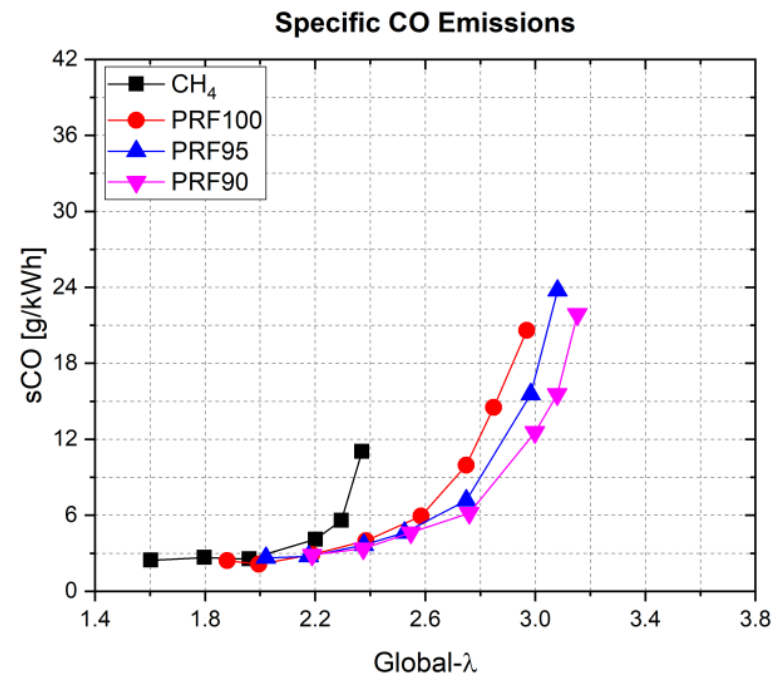

(c)

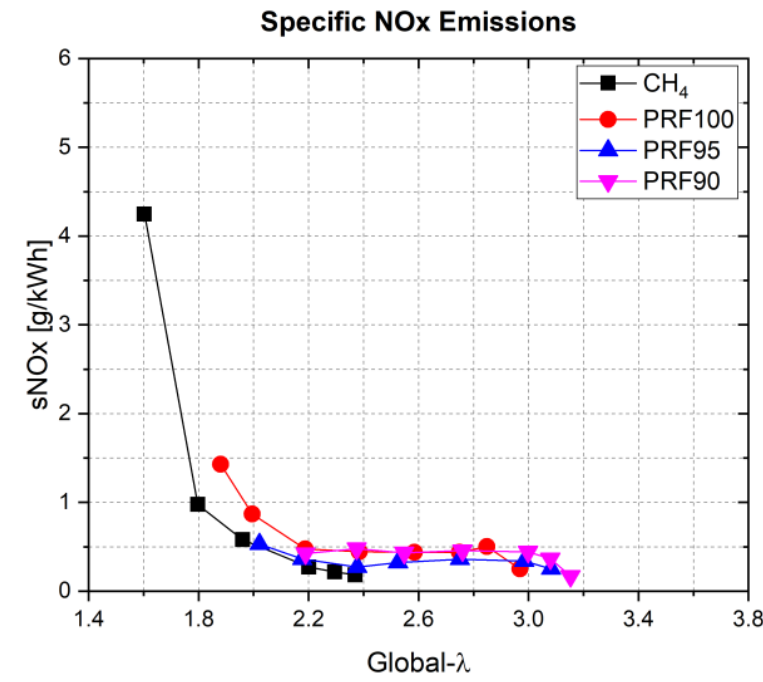

(b)

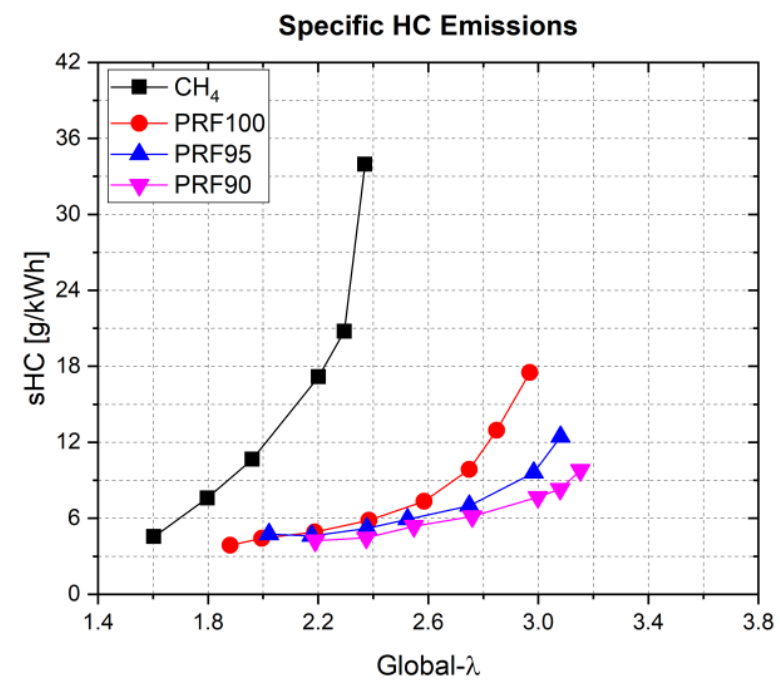

(d)

Figure 8 - Effect of octane number on knock behavior and emissions: (a) Knock intensity, (b) Specific NOx emissions, (c) Specific CO emissions, and (d) Specific HC emissions

\section{Efficiency and Gross Indicated Mean Effective Pressure}

The combustion efficiency, gross indicated mean effective pressure, thermodynamic, and the gross indicated efficiency of methane, and the PRF fuels are presented in this sub-section. The equations used to calculate these efficiencies [18] are provided below, and the terms are explained in the abbreviation section.

$$
\eta_{c o m b}=1-\frac{m_{H C} Q_{L H V, H C}+m_{C O} Q_{L H V, C O}+m_{H_{2}} Q_{L H V, H_{2}}}{m_{f} Q_{L H V, f}}
$$

Total FuelMEP $=\frac{\left(m_{f, P C} \times Q_{L H V, f, P C}\right)+\left(m_{f, M C} \times Q_{L H V, f, M C}\right)}{V_{\text {Displacement }}}$

$$
Q M E P=\eta_{\text {comb }} \times \text { Total FuelMEP }
$$

$$
\begin{gathered}
\eta_{\text {therm }}=\frac{I M E P g}{Q M E P} \\
\eta_{\text {gross-indicated }}=\frac{I M E P g}{\text { Total FuelMEP }}
\end{gathered}
$$

As noted in Figure 9 (a), due to its high specific $\mathrm{CO}$ and $\mathrm{HC}$ emissions, the combustion efficiency of methane is lowest at any given global- $\lambda$ except for global- $\lambda$ 1.6. For any given global- $\lambda$, fuels with lower octane number show higher combustion efficiency due to the lower combustion losses, as described in the previous subsection. Beyond global- $\lambda 2.6$, the combustion stability starts to affect the combustion efficiency for all the fuels. With PRF fuels, the combustion stability is maintained above $90 \%$ except at the lean limit in PRF100 and PRF95 results.

In Figure 9 (b), the gross IMEP values are plotted. Similar to the combustion efficiency trend, the gross IMEP generated with methane is marginally less than the PRFs for a given global- $\lambda$. For the PRF cases, between the knock limit and global- $\lambda 2.4$, the higher

Page 10 of 22

$01 / 28 / 2020$ 
octane fuels have marginally higher gross IMEP values. Within this global- $\lambda$ range, the lower octane number of fuel results in higher knock intensities. Since heavy knock intensities can exacerbate heat transfer losses, fuels with higher octane ratings show slightly improved gross IMEP until global- $\lambda$ 2.4. The trend is reversed after global- $\lambda$ 2.6, where reduced knock intensities are observed with all the PRFs. At the very lean conditions, the lower octane rating shows slightly improved IMEP for a given global- $\lambda$. However, since the lower heating value and physical properties are similar between the PRF fuels, the IMEP generated is similar between these three fuels.

The thermodynamic efficiency, presented in Figure 9 (c), is improved when heat transfer losses are low and when the effective work generated on the piston is high. As explained in the previous paragraph, the heat transfer losses are exacerbated at knocking cycles, which is reflected in the low thermodynamic efficiency with PRF fuels between global- $\lambda 1.9$ and 2.4. Beyond this range, the thermodynamic efficiency improves steadily as the global- $\lambda$ becomes leaner. With methane, since the knock intensities are very low across the global- $\lambda$ range, this fuel typically shows much improved thermodynamic efficiency over the PRFs.

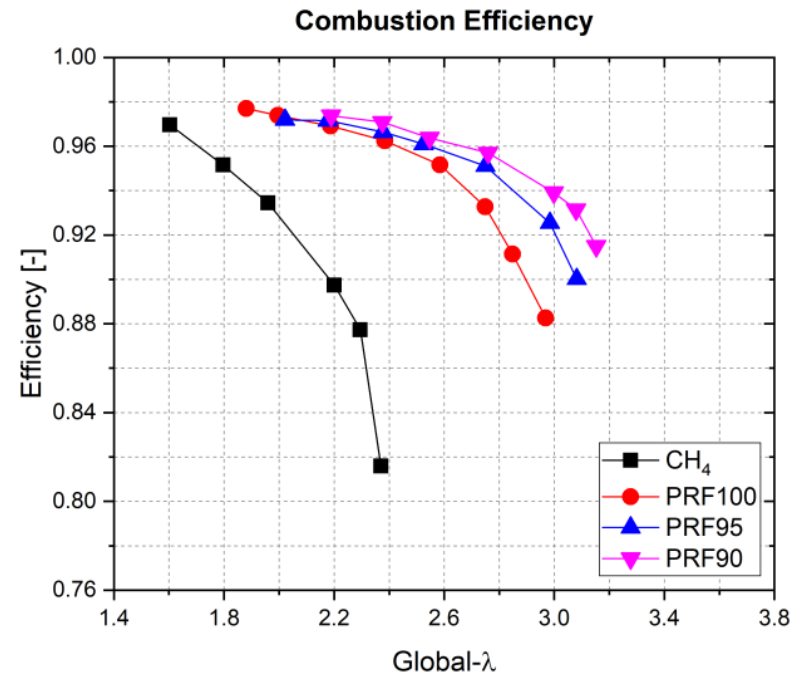

(a)

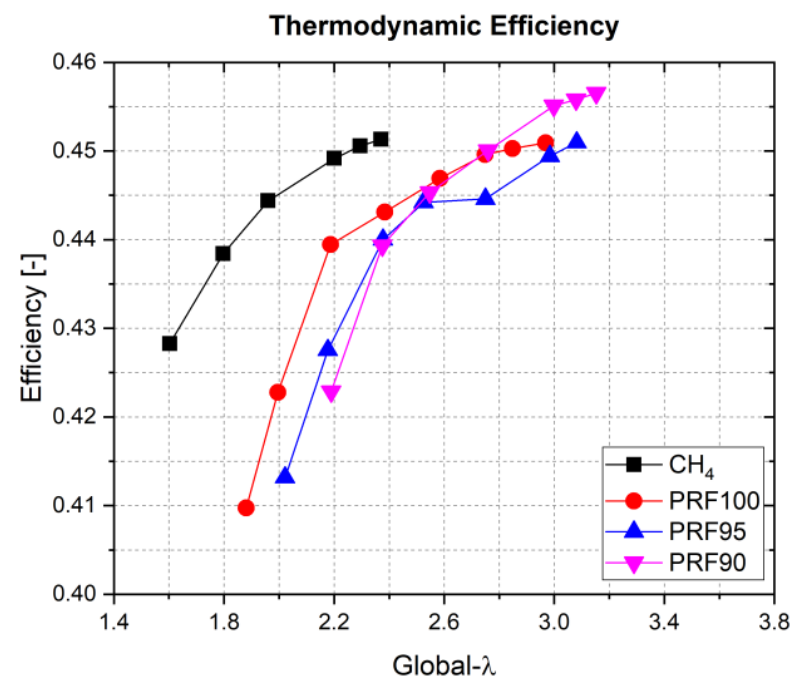

(c)
Since the gross IMEP results between the PRFs are similar, the thermodynamic efficiencies for these cases are also similar, with around $0.5 \%$ variation from one fuel to another between global- $\lambda 2.6$ to the lean limit.

As shown in Figure 9 (d), despite having a high thermodynamic efficiency, the combustion efficiency of methane is rather poor, resulting in the gross indicated efficiency of methane being less than $42 \%$ across the whole global $\lambda$ range. In the case of PRFs, due to low thermodynamic efficiency owing to heavy knock, the gross indicated efficiency is below $42 \%$, near the knock limit. Near the lean limit, the combustion efficiency becomes poor again, which results in a corresponding decline in gross indicated efficiency. A critical observation is that the global- $\lambda$, which gives the peak gross indicated efficiency is at 2.2,2.6, and 2.8, respectively, for the PRF100, PRF95, and PRF90. Therefore, the gross indicated efficiency is not compromised when operating at extended lean conditions, achievable by the lower octane rating of the fuel. The PRF90 shows marginally improved gross indicated efficiency, which peaks at $43 \%$ compared to the other fuels.

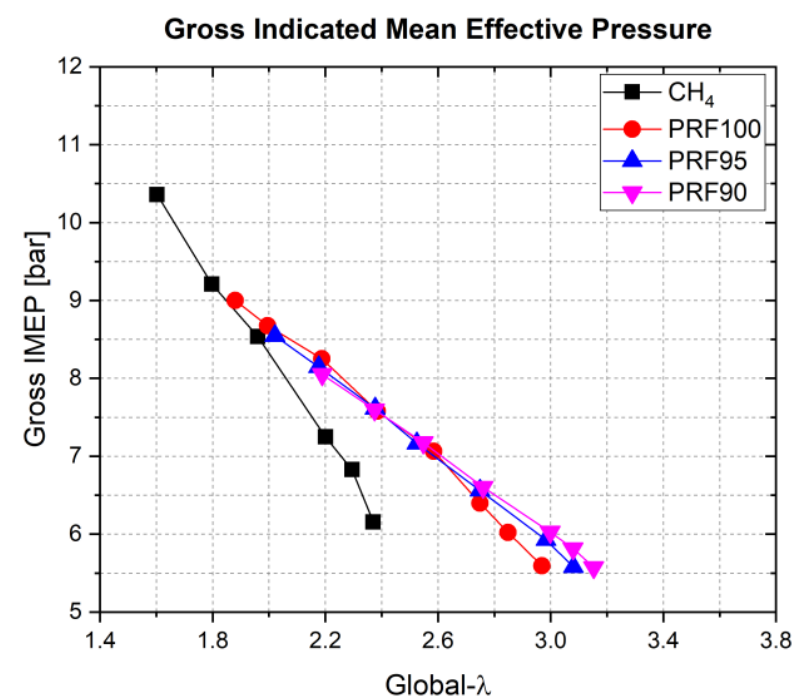

(b)

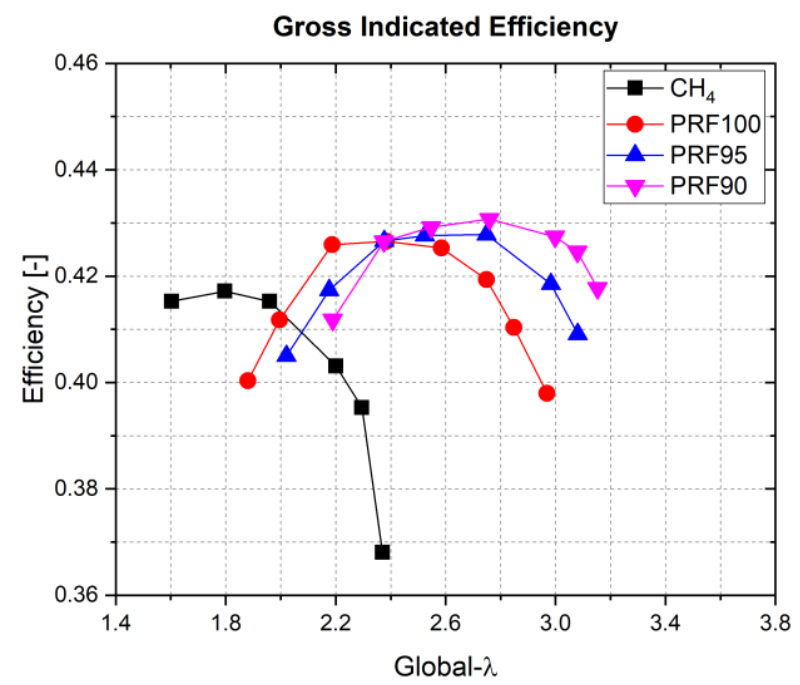

(d)

Figure 9 - Effect of octane number on engine efficiencies and work output: (a) Combustion efficiency, (b) Gross IMEP, (c) Thermodynamic efficiency, and (d) Gross indicated efficiency

Page 11 of 22 


\section{Effect of Fuel Sensitivity of Main Chamber Fuel}

In this section, the PCC operation results with methanol and ethanol as main chamber fuel are analyzed in three sub-sections, similar to the previous section. Although methanol and ethanol have similar RON values, methanol has a MON value of 92 while the MON of ethanol is 89 . Hence, ethanol has a higher sensitivity than methanol. Since these two fuels have different sensitivities $(S=R O N-M O N)$, the experimental outcomes are different from methane and PRFs, which have zero sensitivity. The results from the previous sections are greyed out, and the data from sensitive fuels are overlaid in all the plots for ease of comparison. The symbols depicting the results from the methane and PRF fuels are still conserved in the plots.

\section{Operating Characteristics}

The combustion stability, pressure buildup in the pre-chamber, duration between the spark timing and the $10 \%$ heat release, and the combustion duration are addressed in this section for the alcohols.

In Figure 10 (a), methanol shows the most extended lean limit in all the six fuels under investigation with CoV of IMEPg $<3 \%$, even at the global- $\lambda$ of 3.2. Although ethanol has similar RON values with methanol, the lean capability of this fuel is inferior to methanol and has a lean limit close to that of the PRF100. Methanol also tends to have higher combustion stability than ethanol.

As in the previous cases with methane and the PRFs, the spark timings need to be advanced as the global- $\lambda$ becomes leaner, which can be observed in Figure 10 (b). In general, the MBT spark timings with ethanol are observed to be earlier than all the fuels except methane. The reason is to counter the long combustion duration of ethanol, which is only shorter than methane at any given global- $\lambda$. The combustion duration (CA10-90) of these fuels are shown in Figure 10 (f).

Due to the spark advance, pre-chamber $\lambda$ is also found to be slightly richer with ethanol when compared to methanol and the PRFs, as noted in Figure 10 (c). Apart from methane, the ethanol cases show a richer pre-chamber $\lambda$ than other fuels before the lean limit. At the lean limit, spark timings need to be advanced significantly, which causes the pre-chamber to become rich again for all the fuels.

The pre-chamber pressure buildup is similar between the two alcohols, with methanol showing slightly higher pressure buildup than ethanol, as presented in Figure 10 (d). The higher pressure buildup with methanol is justified since the pre-chamber $\lambda$ in the methanol cases are closer to stoichiometry when compared to ethanol.

Similar to the pressure buildup in the pre-chamber, the delay between spark timing and $10 \%$ of heat release is also very similar between the two fuels, as reported in Figure 10 (e). When compared to methane, the duration is much less for the two alcoholic fuels. Beyond global- $\lambda$ 2.2, the methanol and ethanol results are slightly less than PRF100 but marginally higher than PRF95 and PRF90.

The combustion duration CA10-90 is presented in Figure 10 (f). For the alcohols, the rate at which the combustion duration increases with increasing global- $\lambda$ is not as sharp as with the PRF mixtures. At all global- $\lambda$ conditions, methanol shows shorter combustion durations than ethanol consistently. The latter fuel also shows longer combustion durations than the PRFs at any global $-\lambda$. Similarly, methanol also has higher combustion durations than the PRFs except at the lean limit of the PRFs, where combustion is more stable with methanol. Remarkably, with methanol, the combustion durations are kept below $20 \mathrm{CAD}$ apart from the lean limit at global $-\lambda=3.4$.

\section{Knock and Indicated Specific Emissions}

In this sub-section, the knock intensity and specific NOx, carbon monoxide, and unburned hydrocarbon emissions are discussed for the alcohols and methane, and the PRFs.

Similarly to methane, the methanol and ethanol do not exhibit excessive knock intensities, and the knock limit of 10 bar is not realized, as reported in Figure 11 (a). Methanol and ethanol have 106 and 107 RON, respectively, and only trace knock (less than 3 bar knock intensity) is observed even at global- $\lambda$ 1.6. Hence, the knock trend with sensitive fuels deviates from the trend observed with zero sensitivity fuels. In general, methanol has a slightly higher knock intensity than ethanol. It is recognized that both ethanol and methanol have high latent heat of vaporization. However, since the fuel is injected when the inlet valves are closed, the charge cooling effect, which could prevent knock, should be minimal. Hence, knock avoidance with these fuels could be primarily due to fuel property and the fast combustion rates of the PCC concept. For both methanol and ethanol, a single-cycle main chamber pressure trace at the highest knock intensity attained at the smallest global- $\lambda$ is presented in Appendix A (see Figure A.1).

Figure 11 (b) further confirms that the specific NOx emissions values are primarily influenced by the global- $\lambda$ and less sensitive to fuel properties. As with the methane case, the global- $\lambda$ of 1.6 cases shows the highest specific NOx emissions for methanol and ethanol. However, beyond the global- $\lambda$ of 2.0, the specific NOx emissions fall below $1.0 \mathrm{~g} / \mathrm{kWh}$ and maintain a stable value of around 0.5 $\mathrm{g} / \mathrm{kWh}$ until the lean limit. For all the cases, methanol fuel consistently shows higher specific NOx emissions when compared to ethanol. The difference is most pronounced at global- $\lambda$ 1.6.

As shown in Figure 11 (c), the specific carbon monoxide emissions from ethanol are higher than methanol and the rest of the fuels for most operating conditions. Between global- $\lambda 1.6$ and 2.0, methanol shows slightly higher specific $\mathrm{CO}$ emissions than ethanol. Beyond global- $\lambda 2.0$, although methanol has an advantage over ethanol, the specific CO emissions are around $2 \mathrm{~g} / \mathrm{kWh}$ higher than the PRF fuels before the combustion stability worsens with these more reactive fuels.

Similarly, in Figure 11 (d), the specific hydrocarbon emissions are higher with the alcohols than the zero-sensitivity fuels for stable operating conditions. As in the previous case, the hydrocarbon emissions from ethanol are also significantly higher than methanol.

However, high specific $\mathrm{CO}$ and $\mathrm{HC}$ emissions are expected with alcoholic fuels. The specific fuel consumption for these fuels is considerably higher than methane and the PRFs, owing to the low calorific value of these fuels. Although methanol has a lower heating value than ethanol, the unburned carbon monoxide and hydrocarbon emissions are higher with ethanol. Since ethanol has a higher fuel sensitivity than methanol, the sensitivity might be related to the inefficient combustion with ethanol. 


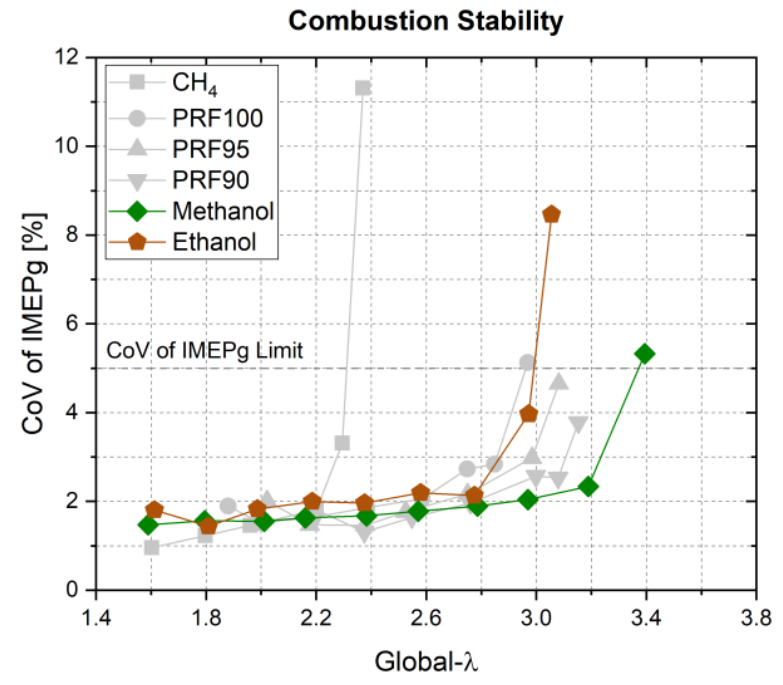

(a)

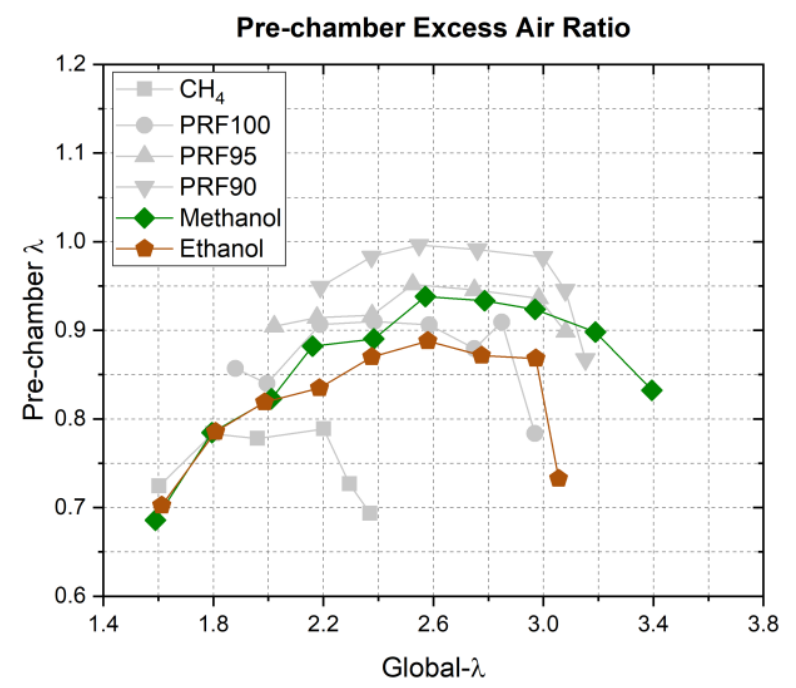

(c)

Duration between Spark Timing and 10\% Heat Release

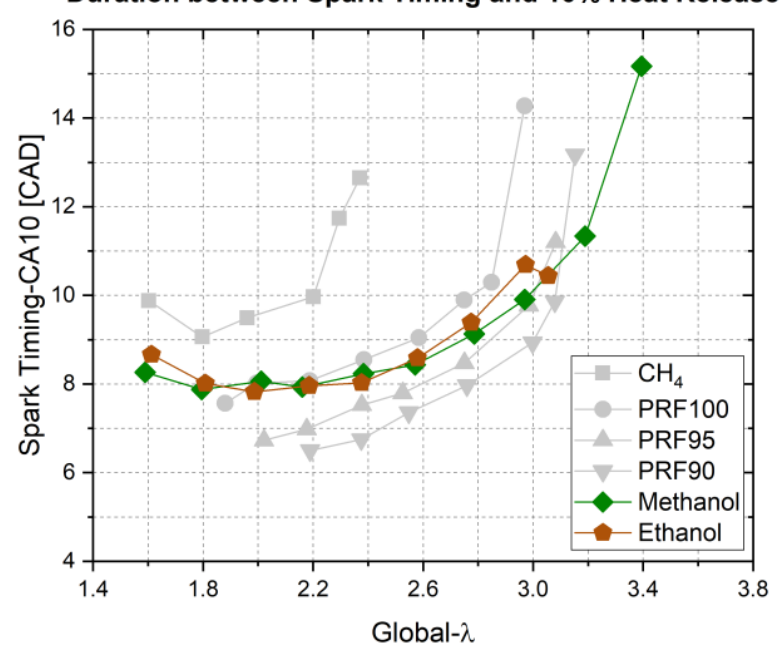

(e)

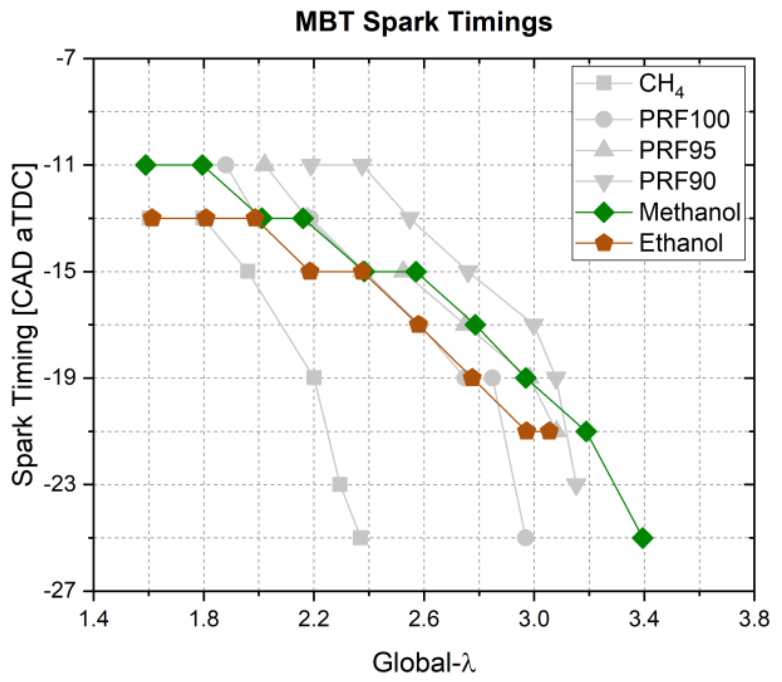

(b)

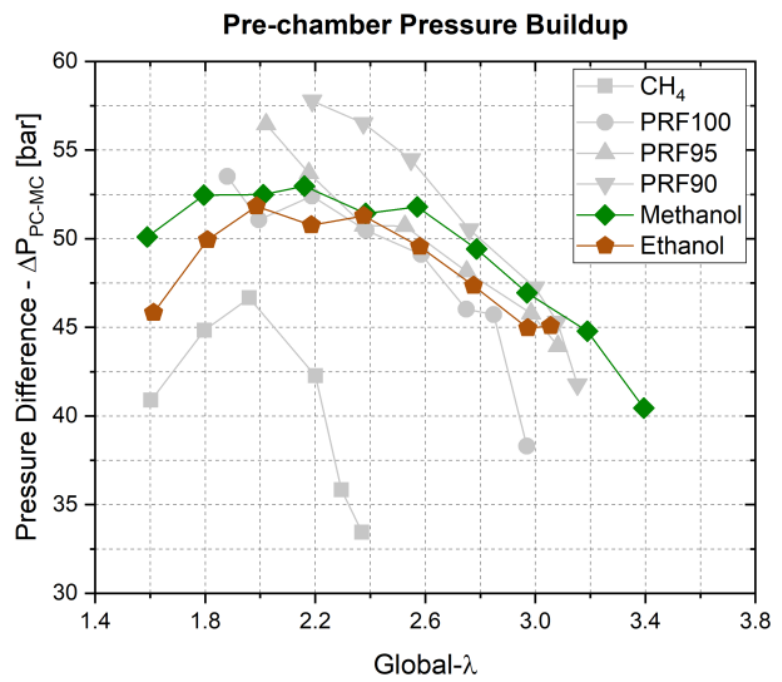

(d)

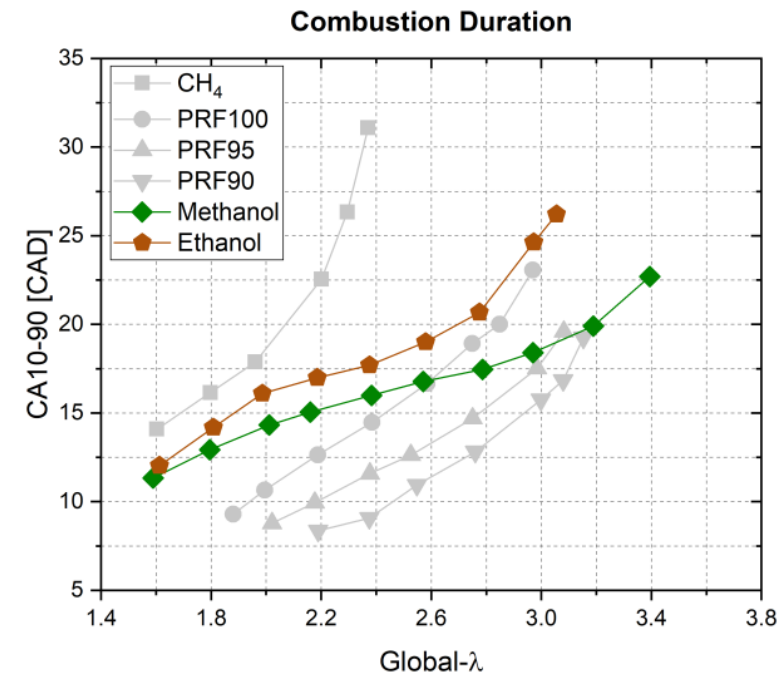

(f)

Figure 10 - Effect of fuel sensitivity on operating characteristics: (a) Combustion stability, (b) MBT spark timings, (c) Pre-chamber $\lambda$, (d) Pressure buildup in the pre-chamber, (e) Duration between spark timing and 10\% heat release, and (f) Duration between 10\% and $90 \%$ heat release

Page 13 of 22

$01 / 28 / 2020$ 


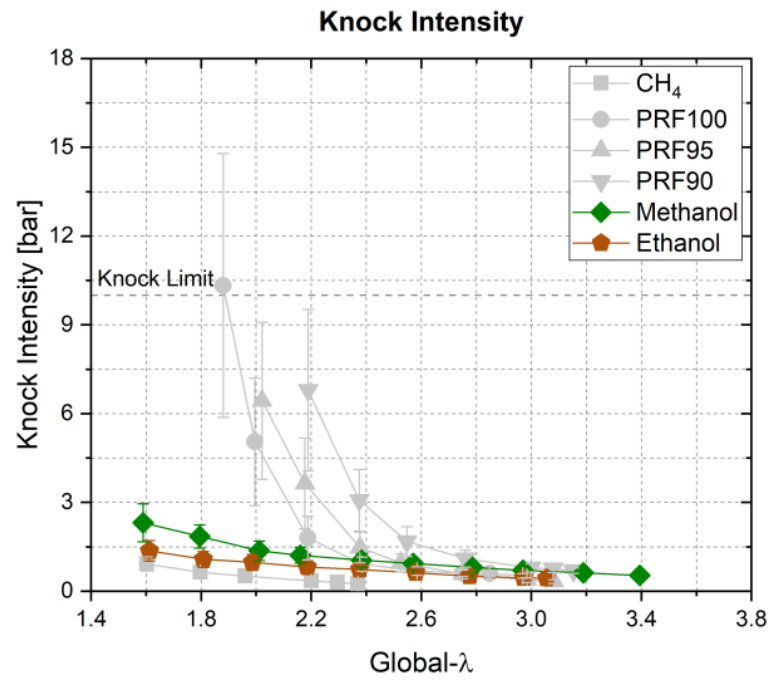

(a)

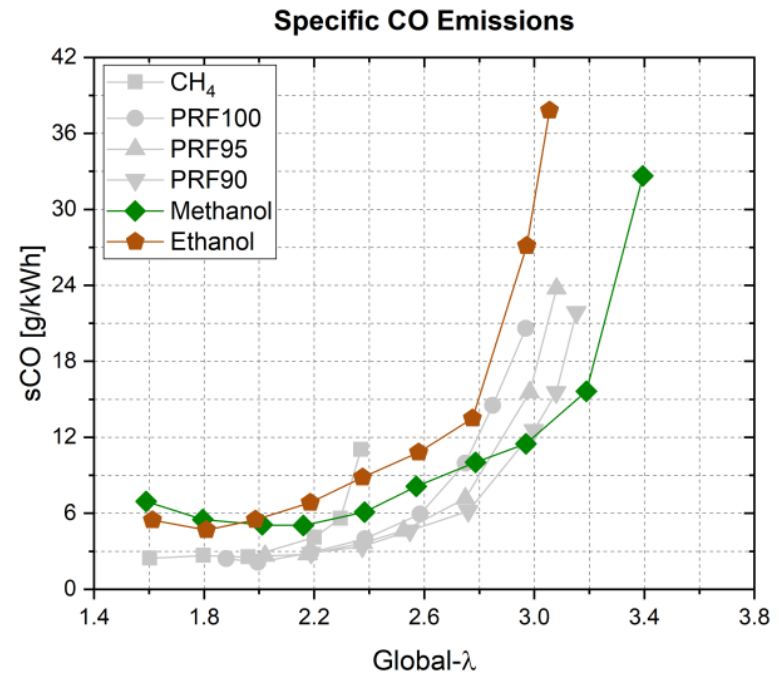

(c)

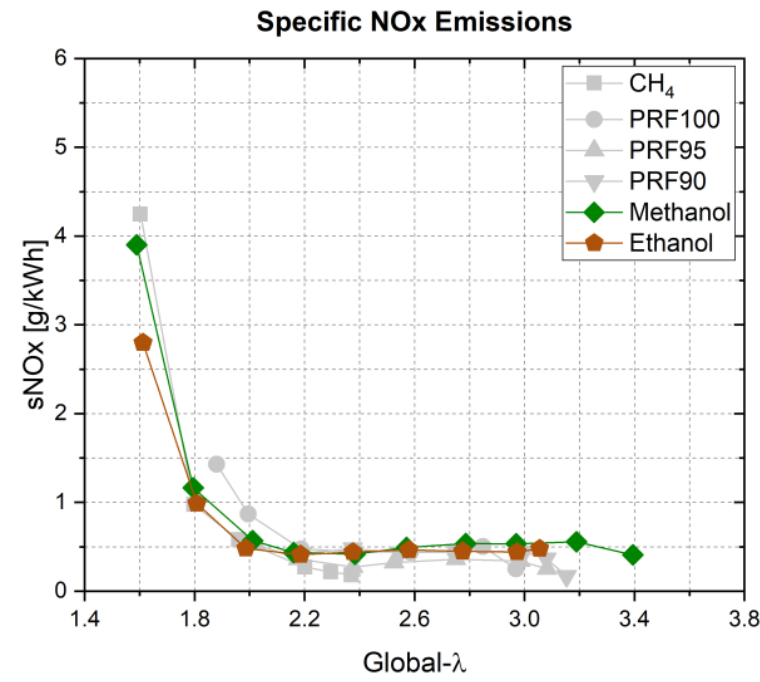

(b)

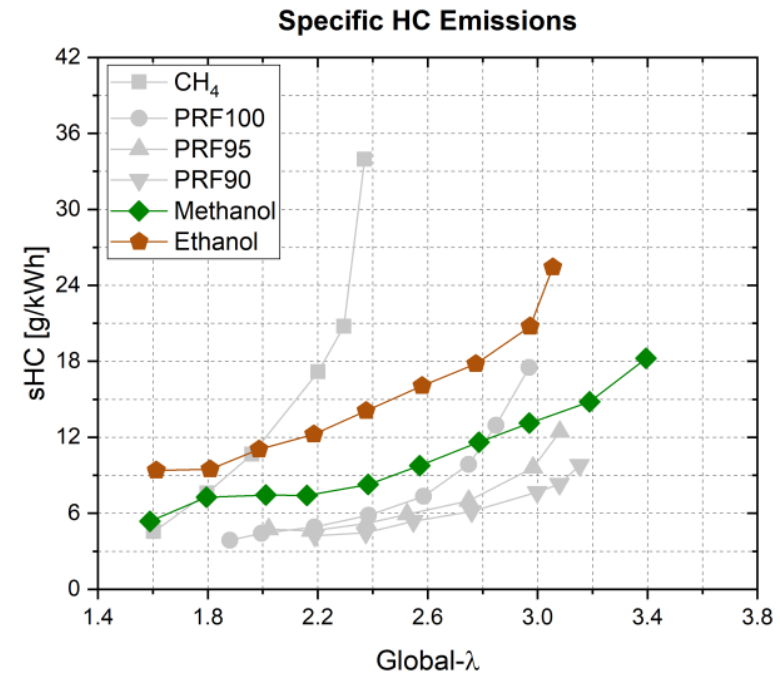

(d)

Figure 11 - Effect of fuel sensitivity on knock behavior and emissions: (a) Knock intensity, (b) Specific NOx emissions, (c) Specific CO emissions, and (d) Specific HC emissions

\section{Efficiency and Gross Indicated Mean Effective Pressure}

The efficiency results and the gross IMEP achieved by methanol and ethanol is discussed in this sub-section.

As observed in Figure 12 (a), ethanol shows poor combustion efficiency, which is the lowest among all the fuels utilized in this study, apart from methane and unstable combustion cases with PRF100. In our previous studies [13,14], ethanol has always shown poor combustion efficiency, especially at ultra-lean conditions $(\lambda>$ 2.0). On the other hand, methanol exhibits high combustion efficiencies for a wide range of global- $\lambda$, maintaining more than $90 \%$ of combustion efficiency even at the lean limit.

The gross IMEP values are plotted for the six fuels in Figure 12 (b). At any global- $\lambda$, methanol provides the highest gross IMEP compared to the rest of the fuels. On the other hand, ethanol generates slightly higher gross IMEP when compared to methane. The gross IMEP values achieved with ethanol is similar to that of the PRF fuels. Figure 12 (c) shows that the thermodynamic efficiency of the methanol and ethanol is inferior to that of methane for the given global- $\lambda$ range. However, as in the case with combustion efficiency and gross IMEP, methanol consistently outperforms ethanol. Apart from the knock-limited global- $\lambda$ of the PRFs, ethanol has a considerably less thermodynamic efficiency than the rest of the fuels. With methanol, the thermodynamic efficiency is slightly higher than the PRFs due to knock avoidance prior to global- $\lambda$ 2.8. Beyond this global- $\lambda$, the thermodynamic efficiency with methanol declines below PRFs.

As shown in Figure 12 (d), methanol fuel shows similar gross indicated efficiency to the PRF fuels, with a peak efficiency of $43 \%$ between global- $\lambda 2.2$ and 2.6. Since methanol can operate with adequate combustion stability across a wide range of global- $\lambda$, the gross indicated efficiency is maintained above $40 \%$ up to global $-\lambda=$ 3.2. Due to poor combustion and thermodynamic efficiency, the gross indicated efficiency of ethanol is considerably lesser than that of methanol. Compared to PRFs, apart from the knock limit, ethanol has a significantly lower gross indicated efficiency. 


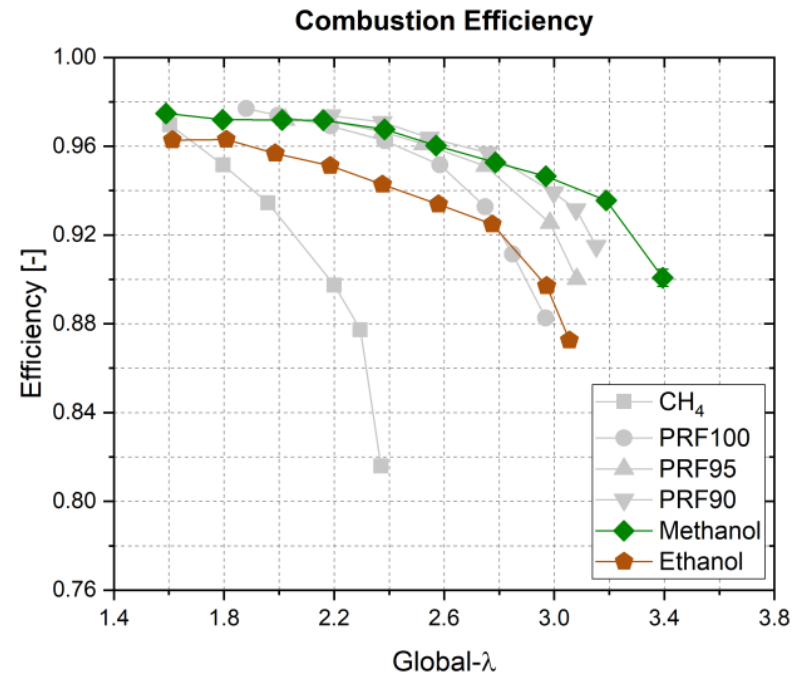

(a)

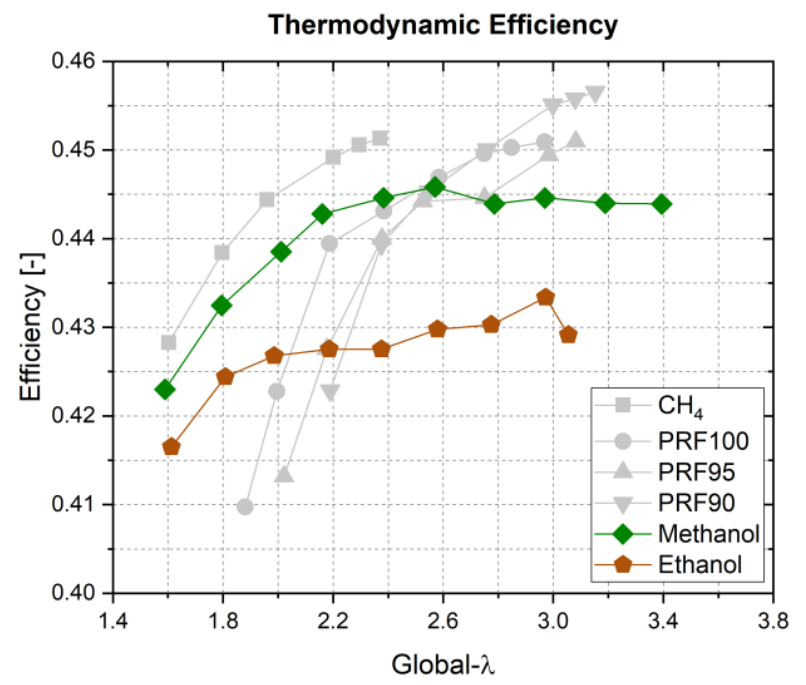

(c)

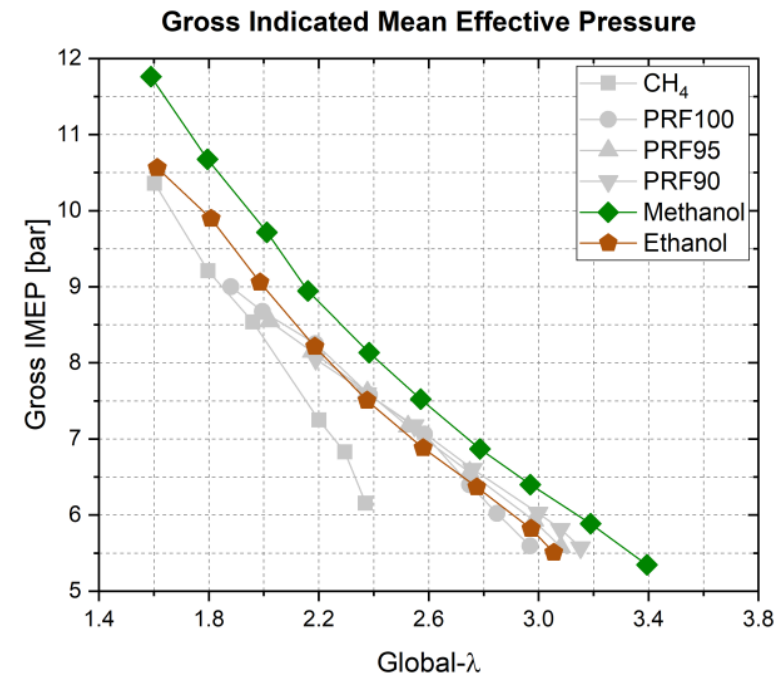

(b)

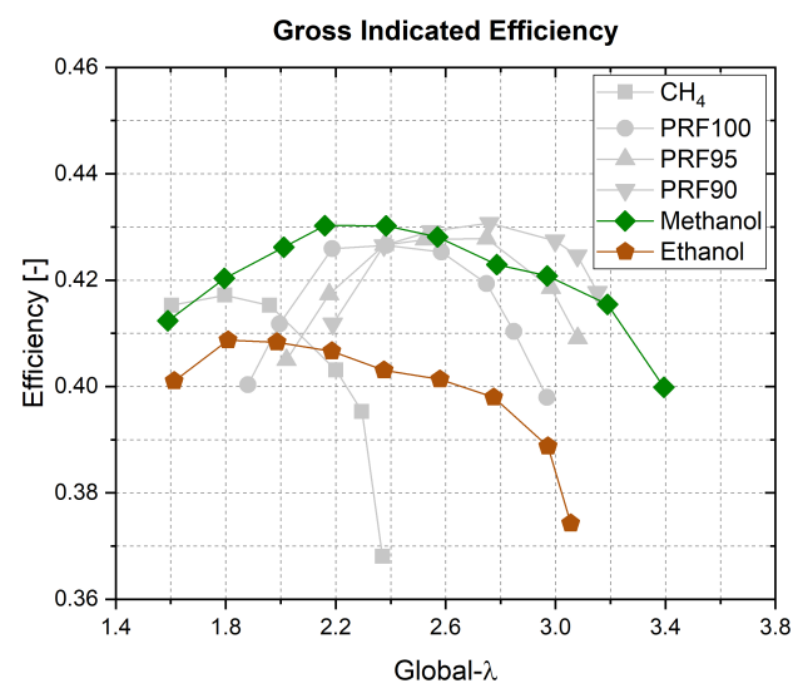

(d)

Figure 12 - Effect of fuel sensitivity on engine efficiencies and work output: (a) Combustion efficiency, (b) Gross IMEP, (c) Thermodynamic efficiency, and (d) Gross indicated efficiency

\section{Heat Release Analysis}

In this section, the rate of heat release profiles for all six fuels are presented. Understanding the process of main chamber ignition by the pre-chamber jets has been studied extensively in recent years. Biswas et al. [29] fathomed that the main chamber ignition could be achieved by two mechanisms: flame ignition and jet ignition, depending on the nozzle hole diameter. The findings are based on the constant volume combustion chamber experiments. The flame ignition mechanism refers to the ignition of the main chamber charge by flames coming out of the pre-chamber nozzles. In the jet ignition mechanism, the jets are partially quenched upon passing through the nozzle, and only hot burned gases are issued, prompting ignition of the main chamber charge at a distance from the nozzle.

In our recent investigations in a similar engine with optical access, only the flame ignition mechanism is observed $[20,21,30]$. Biswas et al. [29] also stated that flame ignition is prevalent at elevated pressures. Therefore, the flame ignition mechanism could be the dominating ignition mechanism in real engine operations with a prechamber. In 2019, Malé et al. [31] performed a large eddy simulation

Page 15 of 22 of pre-chamber ignition in engine configuration. Furthermore, the pressure buildup that the group reported is around $40 \mathrm{bar}$, similar to our studies. They proposed that the main chamber combustion process consists of three sequences, which are briefly explained as follows:

(a) Ignition by hot gases ejection (IHG) - where the prechamber jets are issued to the main chamber, mixes with the lean main chamber charge.

(b) Combustion sustained by hot gas ejection (CSHG) where the flame fronts start to appear and are sustained by the thermal energy and turbulence from the jets until the pressure between the two chambers equalizes.

(c) Combustion unsustained by hot gas ejection (CUHG) the flame fronts start to propagate through the combustion chamber, burning the fresh unburned charge.

The main chamber rate of heat release profile for a cycle with low knock intensity is provided in Figure 13 (a). The main chamber rate of heat release is presented with a solid line, and a dotted line is reserved for the pre-chamber heat release, multiplied five times for visibility. The pressure difference between the pre-chamber and the 
main chamber is illustrated with a dashed line. The pre-chamber rate of heat release is a gaussian shape, typical of SI flame propagation.

The three sequences proposed by Malé et al. [31] can be observed in the main chamber rate of heat release. The first sequence, IHG, starts when the pressure buildup in the pre-chamber is half of the maximum value. This stage coincides with the period where the visible jets are detected in the previous optical engine experiments $[20,21,30]$. The second stage, CSHG, can be observed with a distinct change in the slope of the heat release rate near the end of prechamber pressure buildup, close to the $\Delta P$ reversal 2. After $\Delta P$ reversal 2 , the heat release rate increases again, indicating the flame front propagation in the main chamber from the multiple ignition sites. As shown in Figure 13 (b), a sudden rise in heat release rate is observed in cases with considerable knock intensity near the end of the main chamber heat release after the third sequence (CUHG). The rise in heat release rate signifies end gas auto-ignition (EGA), otherwise termed as knock.

\section{Events of MC Heat Release (Low Knock Intensity)}

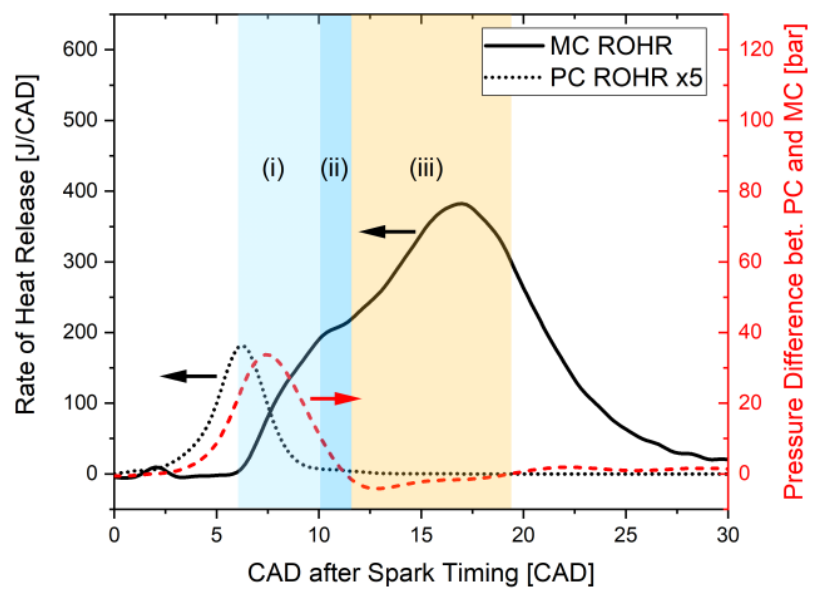

(a)

Events of MC Heat Release (High Knock Intensity)

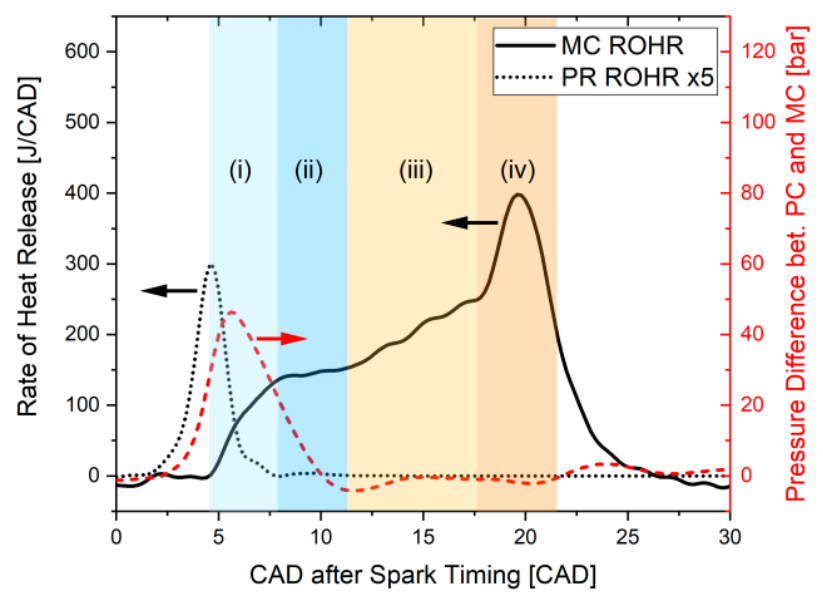

(b)

Figure 13 - Events of main chamber heat release for (a) Low knock intensity operation and (b) High knock intensity operation. Event: (i) Ignition by hot gas ejection (IHG), (ii) Combustion sustained by hot gas ejection (CSHG), (iii) Combustion unsustained by hot gas ejection (CUHG), and (iv) End gas auto-ignition (EGA).
The rate of heat release plots (500 cycles averaged) for all the six fuels in this study are plotted in Figure 14. For clarity, only even global- $\lambda$ cases are presented, and the colors are conserved for each global- $\lambda$ cases in different fuels. Similarly to Figure 13, the solid lines are used for the main chamber rate of heat release, while the dotted lines represent the pre-chamber rate of heat release. The latter is multiplied five times for visibility.

As shown in Figure 14 (a), (b), and (c), there is no discernable end gas auto-ignition (EGA) event with methane, methanol, and ethanol fuels, since the knock intensities are low with these fuels. On the other hand, the PRF fuel cases show significant auto-ignition events between global- $\lambda$ 2.0-2.4. With PRF90, some levels of auto-ignition persist even at global- $\lambda$ 3.0. In general, for a given global- $\lambda$, the higher the chemical reactivity of the fuel, the more heat release is observed in the EGA. In contrast, in fuels with lower reactivity, i.e., with a higher octane rating, EGA is non-existent. Methanol shows a significantly higher main chamber rate of heat release for a given global- $\lambda$ when compared to methane and ethanol.

As shown in Figure 14 (a), the pre-chamber rate of heat release for methane cases is lower than all other fuels since the pressure buildup in the pre-chamber is lower. Apart from methane, the pre-chamber heat release rates are similar for the other fuels since the prechamber pressure buildup is also similar for these fuels.

As the global- $\lambda$ increases, the heat release rate decline, and the combustion duration becomes extended for all the fuels in this study. Although the pre-chamber rate of heat release is fairly constant for a wide global- $\lambda$ range (apart from the lean limit), the heat release in the main chamber from IHG contributions becomes lower as the main chamber becomes progressively leaner. This observation agrees with Malé et al. [31], as they recognized that the IHG phase is limited by chemistry since mixing is very fast during this phase, thanks to the high turbulence intensity provided by the pre-chamber jets.

The CSHG stage, where the combustion is sustained by the prechamber jets, appears to be relatively flat compared to other sequences in the main chamber heat release. A shallow gradient in CSHG can be found with methane at global- $\lambda$ 1.6, but the gradient becomes flat as the main chamber charge becomes leaner. The CUHG, on the other hand, is influenced by fuel chemistry. The heat release from this sequence is predominantly through flame propagation, and hence, for a given global- $\lambda$, fuels with higher flame speeds show a faster rate of heat release. For instance, the main chamber rate of heat release during the CUHG stage for global $-\lambda=$ 2.2 (brown line in Figure 14) becomes more intense from PRF100 to PRF90.

It appears that the flame propagation speed is an important parameter to further understand the heat release process in the main chamber, especially for the CUHG stage. However, the operating conditions are typically lean, especially for the PRF mixtures where the operation range lies between global- $\lambda 2.0$ and 3.0. At these ultralean conditions, the laminar flame speed data of the fuels in this study are not readily available in the literature. Hence, chemical kinetics simulations at ultra-lean conditions are reserved for the future, which might improve the understanding of engine-fuel interaction in a PCC engine. 
Methane

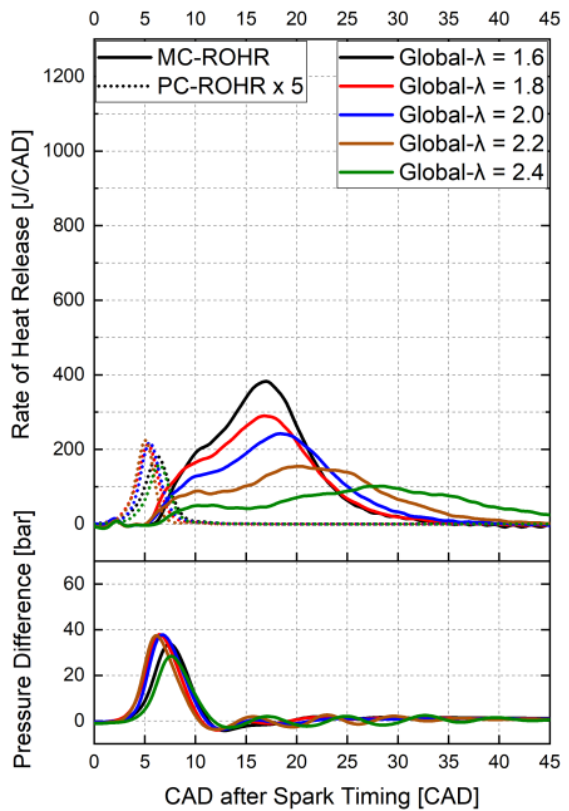

(a)

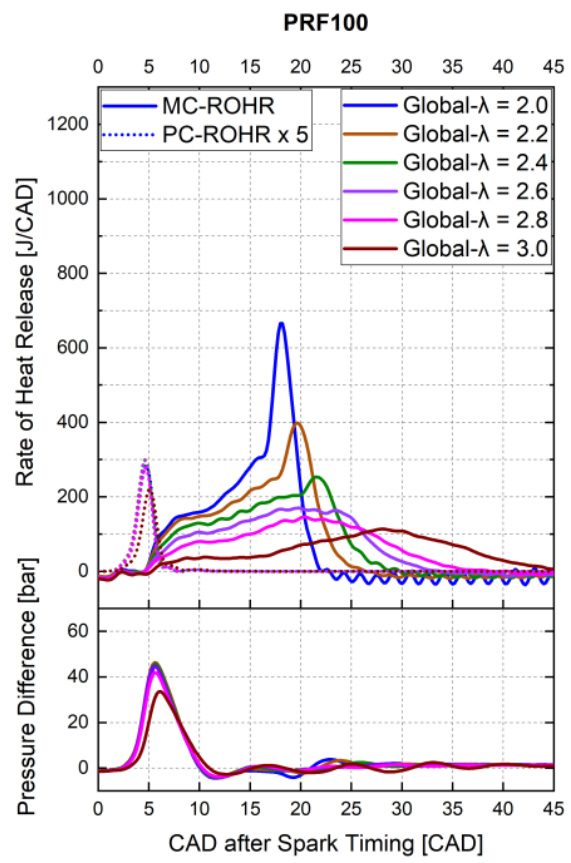

(d)
Methanol

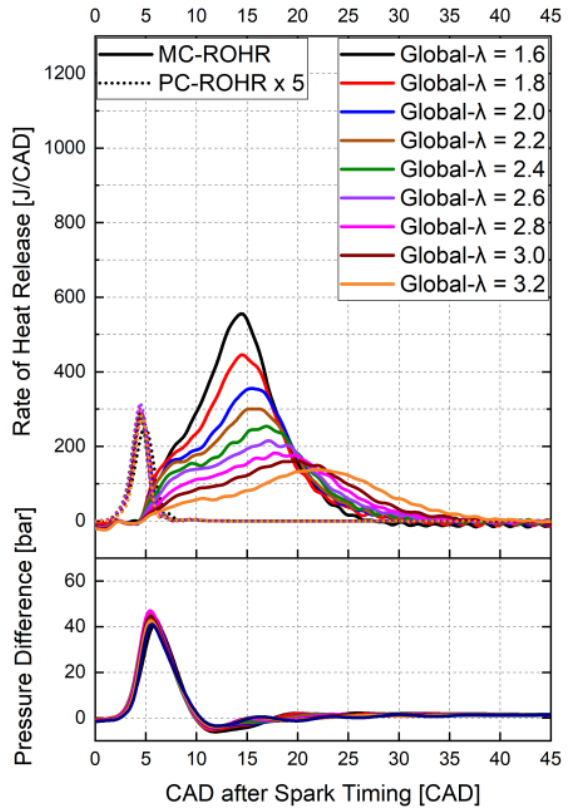

(b)

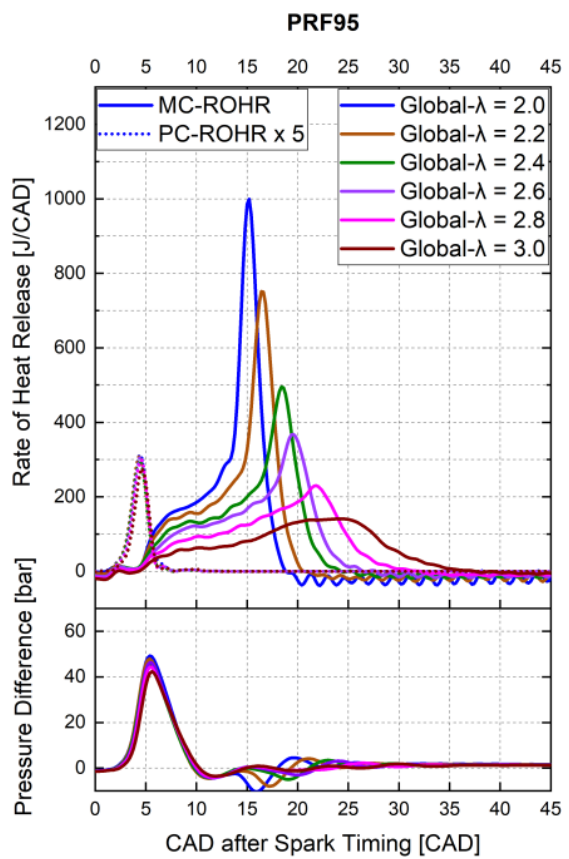

(e)
Ethanol

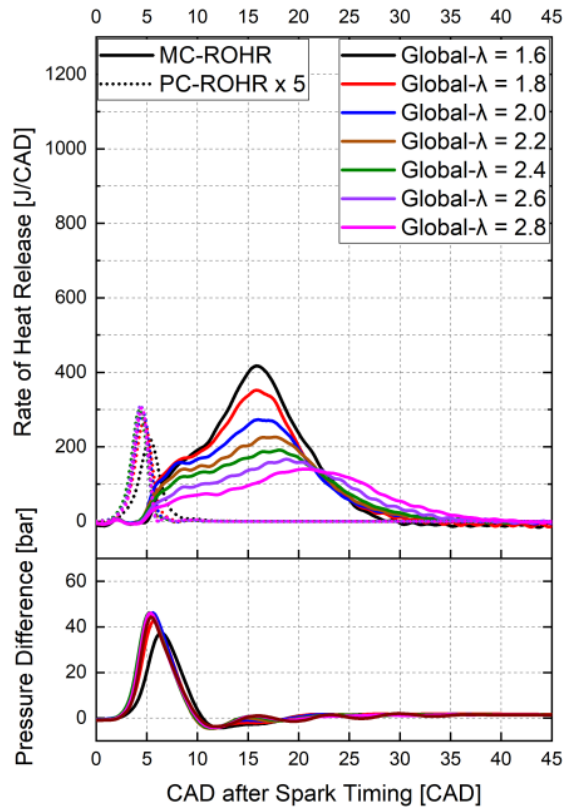

(c)

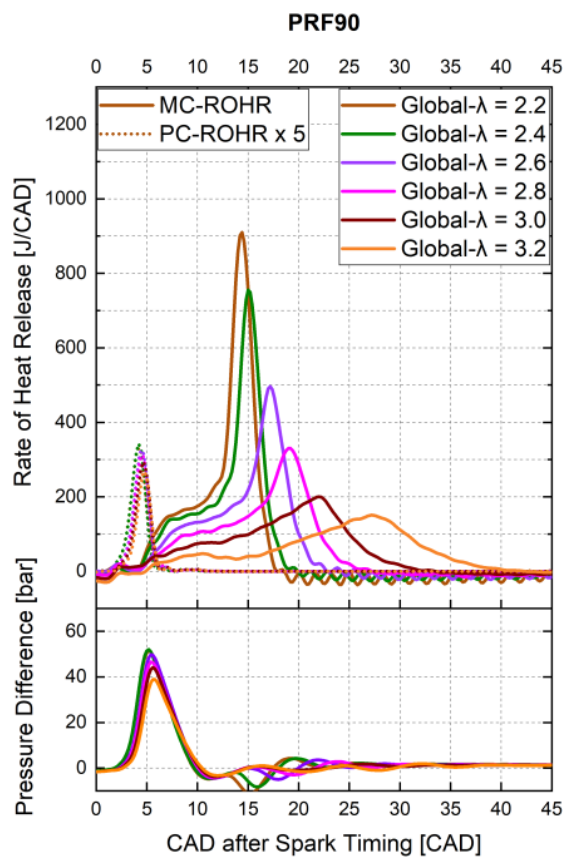

(f)

Figure 14 - Rate of Heat release for the main chamber, pre-chamber, along with pressure buildup in the pre-chamber: (a) Methane, (b) Methanol, (c), ethanol, (d) PRF100, (e) PRF95, and, (f) PRF90 (Solid lines represent main chamber rate of heat release. Dotted lines represent the pre-chamber rate of heat release multiplied five times.

As the global- $\lambda$ becomes leaner, the main chamber charge declines in reactivity, making it harder to ignite. Near the lean limit, the probability of successful ignition starts to dwindle, causing frequent misfires, although the pre-chamber still provides the jets reliably. When a misfire occurs, although the contribution to the main chamber rate of heat release from the IHG stage is still significant, the jets could not sustain the CSHG stage, indicated by the downward gradient of the main chamber heat release as shown in Figure 15. As a result, the CUHG stage also fails, resulting in the main chamber misfire. A typical misfire cycle is presented alongside a normal operating cycle, as shown in Figure 15. 


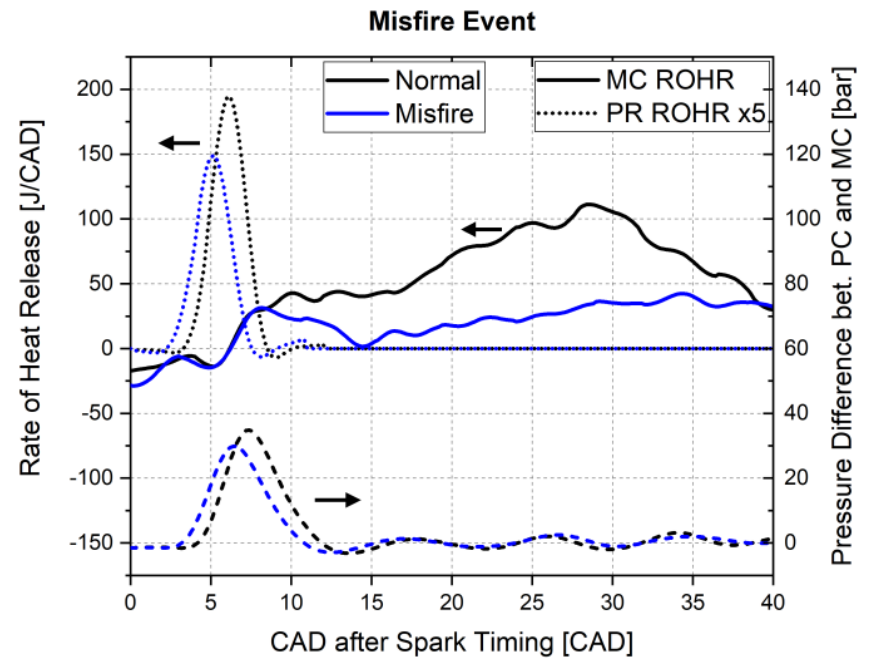

Figure 15 - Comparison between a normal operating cycle and a misfire cycle

\section{Summary}

In this study, the pre-chamber was fueled with methane, and the prechamber FuelMEP ratio (PCFR) was kept at $13 \%$. The main chamber is fueled by six different fuels: methane, PRF100, PRF95, PRF90, methanol, and ethanol. Global- $\lambda$ was varied between 1.6 or the knock limit until the lean limit is reached. The effect of fuel octane number was examined by studying the results with methane, PRF100, 95, and 90 fuels. Each of these fuels has the same RON and MON, and hence the fuel sensitivity is zero. In addition, the results with methanol and ethanol are presented and compared with the four fuels from the previous sections to study the effect of fuel sensitivity in the main chamber.

In all cases, the pre-chamber pressure buildup is significantly higher than the values found in the literature $[11,15,16]$. The pre-chamber employed in this study has a narrow throat diameter of $3.3 \mathrm{~mm}$, and the pre-chamber pressure buildup is typically in excess of 40 bar, which is almost twice higher than the results from the studies mentioned above. The high pressure buildup in the pre-chamber appears to be enhancing the lean limit of the engine. With the narrow-throat geometry, the CoV of IMEPg is only around $2.5 \%$ when global- $\lambda$ is 3.0 with PRF90 as the main chamber fuel.

In contrast, Attard and Blaxill [7] has a lean limit at global- $\lambda 2.0$ with conventional gasoline operation. Therefore, the throat geometry of the pre-chamber appears to be a useful parameter to improve the lean capability of PCC. On the other hand, with the narrow-throat prechamber, high knock tendencies were also observed with the PRF fuels in the vicinity of global- $\lambda$ 2.0. However, knock is suppressed when operating with methanol and ethanol. These findings proved that the fuel characteristic is an additional dimension that needs to be further explored to enhance the understanding of the PCC concept.

The notable observations are summarized below.

1. Since the research engine is based on a diesel engine, fuel injection into the air intake during the gas exchange period exacerbates unburned hydrocarbon emissions and thus reduces the combustion efficiency. The fuel injection, while the intake valves are closed, improves the vaporization of the injected fuel using the engine's wall-temperature. Not only the hydrocarbon emissions are reduced, but also the lean operating limit is extended by the closed valve injection timing.

2. Combustion with methane shows the most limited operating range since the lean limit is reached around global- $\lambda 2.3$. Methanol shows the highest combustion stability and exhibits the widest operating range of global- $\lambda$, with the lean limit at global- $\lambda$ 3.4. Ethanol and PRF100 have the lean limit around global- $\lambda$ 3.0. By employing lower PRF fuels, it was found that the lean limit can be improved.

3. Although the fraction of fuel energy supplied to the prechamber is kept constant, it is possible that the pre-chamber gains a fraction of the main chamber air-fuel mixture during the compression stroke. Accordingly, even though the PCFR was kept constant at $13 \%$, cases with different main chamber fuel have different levels of pressure buildup in the pre-chamber. Hence, it can be deduced that the pre-chamber mixture composition at the spark timing comprises a considerable portion of fuel injected into the main chamber.

4. The delay between the spark timing and $10 \%$ heat release appears to be closely tied to the pre-chamber pressure buildup. Methane, having the slowest flame speed among the fuels studied, displays the longest delay, while the duration is shorter for PRF90. This delay affects the combustion duration (CA1090 ), and therefore, methane also pertains to the longest combustion duration. On the other hand, results with PRF fuels show very fast combustion rates, and the CA10-90 value is kept below $20 \mathrm{CAD}$ for a wide range of global- $\lambda$ up to 3.0.

5. PRF fuels show excessive knock intensities, and the knock limit of 10 bar is exceeded even when global- $\lambda$ is around 1.9 with PRF100. Methane, methanol, and ethanol can effectively suppress the knock. No end gas auto-ignition (EGA) is detected with these fuels in the main chamber heat release rates. The fuels with sensitivity behave very differently from the zero sensitivity fuels in knock behavior. In future studies, the temperature and pressure trajectory will be analyzed with different fuels to further examine the knocking phenomenon.

6. The NOx emission is relatively insensitive to the fuel properties and is strongly correlated to the global- $\lambda$. The specific CO and $\mathrm{HC}$ emissions are low when operating near the knock limit for PRF fuels. As the global- $\lambda$ increases, the specific $\mathrm{CO}$ and $\mathrm{HC}$ emissions increase, resulting in poor combustion efficiency.

7. The combustion efficiency with methane is poor except at the global- $\lambda$ of 1.6. The efficiency drops at a much faster rate compared to the rest of the fuels. Therefore, the gross indicated efficiency of methane is lower than the PRFs, apart from the knock-limited global- $\lambda$ of the PRFs. Due to poor combustion efficiency and slow combustion, the gross indicated efficiency of this fuel is the lowest among the fuels concerned for stable operating conditions.

8. In the case of PRF fuels, by reducing the octane number of fuel, the gross indicated efficiency can be improved at a leaner global- $\lambda$. Employing fuels with lower octane ratings not only extends the lean limit but also shifts the global- $\lambda$ with peak efficiency to a leaner condition.

9. The sequence of main chamber ignition by the pre-chamber jets can be observed by analyzing the slope of the main chamber rate of heat release. The heat release profiles are in good agreement with the main chamber ignition sequences found in the literature. In fuels with poor knock resistance, such as the PRF fuels, a distinct rise in heat release rate is observed near the end of main chamber combustion, indicating end gas autoignition or knock.

10. The fuel properties, especially the flame speed, appear to be important in understanding the effect of main chamber heat release characteristics on different fuels. However, since the operating conditions are very lean, the laminar flame speed data 
of the fuels considered in this study are not readily available in the literature. In the future, chemical kinetic simulations will be attempted to analyze the flame speed at these ultra-lean conditions to explain the results further.

\section{References}

[1] Shah, A., Tunestal, P., \& Johansson, B., "Investigation of Performance and Emission Characteristics of a Heavy Duty Natural Gas Engine Operated with Pre-Chamber Spark Plug and Dilution with Excess Air and EGR," SAE International Journal of Engines. 5(4):1790-1801, 2012, doi:10.4271/2012-01-1980.

[2] Alvarez, C.E.C., Couto, G.E., Roso, V.R., Thiriet, A.B., \& Valle, R.M., "A review of prechamber ignition systems as lean combustion technology for SI engines," Applied Thermal Engineering. 128:107-120, 2018, doi:10.1016/j.applthermaleng.2017.08.118.

[3] Toulson, E., Schock, H.J., and Attard, W.P., "A Review of Pre-Chamber Initiated Jet Ignition Combustion Systems," SAE Technical Paper 2010-01-2263, 2010, doi:10.4271/2010-01-2263.

[4] Toulson, E., Watson, H.C., \& Attard, W.P., "Modeling Alternative Prechamber Fuels in Jet Assisted Ignition of Gasoline and LPG," SAE Technical Paper 2009-01-0721, 2009, doi:10.4271/2009-01-0721.

[5] Yontar, A.A., "A comparative study to evaluate the effects of pre-chamber jet ignition for engine characteristics and emission formations at high speed," Energy. 210, 2020, doi:10.1016/j.energy.2020.118640.

[6] Stadler, A., Sauerland, H., Härtl, M., \& Wachtmeister, G., "The Potential of Gasoline Fueled Pre Chamber Ignition Combined with Elevated Compression Ratio," SAE Technical Papers. 2020-01-0279, 2020, doi:10.4271/202001-0279.

[7] Attard, W., \& Blaxill, H., "A Single Fuel Pre-Chamber Jet Ignition Powertrain Achieving High Load, High Efficiency and Near Zero NOx Emissions," SAE International Journal of Engines. 5(3):734-746, 2011, doi: 10.4271/2011-01-2023.

[8] Gussak, L.A., Karpov, V.P., and Tikhonov, Y.V., "The Application of Lag-Process in Prechamber Engines," SAE Technical Paper 790692, 1979, doi:10.4271/790692.

[9] Gussak, L., Turkish, M., and Siegla, D., "High Chemical Activity of Incomplete Combustion Products and a Method of Prechamber Torch Ignition for Avalanche Activation of Combustion in Internal Combustion Engines," SAE Technical Paper 750890, 1975, doi: $10.4271 / 750890$.

[10] Gussak, L., "The Role of Chemical Activity and Turbulence Intensity in Prechamber-Torch Organization of Combustion of a Stationary Flow of a Fuel-Air Mixture," SAE Technical Paper 830592, 1983, doi:10.4271/830592.

[11] Shah, A., Tunestal, P., and Johansson, B., "Effect of PreChamber Volume and Nozzle Diameter on Pre-Chamber Ignition in Heavy Duty Natural Gas Engines," SAE Technical Paper 2015-01-0867, 2015, doi:10.4271/201501-0867.

[12] Silva, M., Sanal, S., Hlaing, P., Cenker, E. et al., "Effects of Geometry on Passive Pre-Chamber Combustion
Characteristics," SAE Technical Paper 2020-01-0821, 2020, doi: $10.4271 / 2020-01-0821$.

[13] Hlaing, P., Echeverri Marquez, M., Bhavani Shankar, V., Cenker, E. et al., "A Study of Lean Burn Pre-Chamber Concept in a Heavy Duty Engine," SAE Technical Paper 2019-24-0107, 2019, doi:10.4271/2019-24-0107.

[14] Almatrafi, F., Hlaing, P., Echeverri Marquez, M., Ben Houidi, M. et al., "Narrow-Throat Pre-Chamber Combustion with Ethanol, a Comparison with Methane," SAE Technical Paper 2020-01-2041, 2020, doi:10.4271/2020-01-2041.

[15] Bunce, M., Blaxill, H., Kulatilaka, W., and Jiang, N., "The Effects of Turbulent Jet Characteristics on Engine Performance Using a Pre-Chamber Combustor," SAE Technical Paper 2014-01-1195, 2014, doi:10.4271/201401-1195.

[16] Vedula, R. T., Song, R., Stuecken, T. Zhu, G. G. et al., "Thermal Efficiency of a Dual-Mode Turbulent Jet Ignition Engine under Lean and near-Stoichiometric Operation." International Journal of Engine Research, 18(10):1055-1066, 2017, doi: $10.1177 / 1468087417699979$.

[17] da Costa, R. B. R., Teixeira, A. F., Rodrigues Filho, F. A., Pujatti, F. J. P., Coronado, C. J. R. et al., "Development of a homogeneous charge pre-chamber torch ignition system for an SI engine fuelled with hydrous ethanol," Applied Thermal Engineering. 152:261-274, 2019, doi:10.1016/j.applthermaleng.2019.02.090.

[18] Heywood, J.B., "Internal Combustion Engine Fundamentals," McGraw-Hill, 1998.

[19] Hlaing, P., Echeverri Marquez, M., Singh, E., Almatrafi, F. et al., "Effect of Pre-Chamber Enrichment on Lean Burn Pre-Chamber Spark Ignition Combustion Concept with a Narrow-Throat Geometry," SAE Technical Paper 2020-01-0825, 2020, doi:10.4271/2020-01-0825.

[20] Echeverri Marquez, M., Hlaing, P., Tang, Q., Sampath, R. et al., "High-Speed Imaging of Main-Chamber Combustion of a Narrow Throat Pre-Chamber under Lean Conditions," SAE Technical Paper 2020-01-2081, 2020, doi:10.4271/2020-01-2081.

[21] Sampath, R., Tang, Q., Echeverri Marquez, M., Sharma, P. et al., "Study on the Pre-Chamber Fueling Ratio Effect on the Main Chamber Combustion Using Simultaneous PLIF and $\mathrm{OH}^{*}$ Chemiluminescence Imaging," SAE Technical Paper 2020-01-2024, 2020, doi:10.4271/202001-2024.

[22] Brecq, G., Bellettre, J., \& Tazerout, M., "A new indicator for knock detection in gas SI engines," International Journal of Thermal Sciences. 42(5):523-532, 2003 , doi:10.1016/S1290-0729(02)00052-2.

[23] Duong, J., Andersson, Ö., Hyvönen, J., Álden, M. et al., "High-Speed Combustion Imaging in a Large Bore Gas Engine: The Relationship Between Pre- and Main Chamber Heat Release," V08AT09A022. ASME, 2014, doi:10.1115/IMECE2013-64286.

[24] Sanal, S., Silva, M., Hlaing, P., Cenker, E. et al., “A Numerical Study on the Ignition of Lean CH4/Air Mixture by a Pre-Chamber-Initiated Turbulent Jet," SAE Technical Paper 2020-01-0820, 2020, doi:10.4271/2020-01-0820.

[25] Wenig, M., \& Roggendorf, K., "Development of a Predictive Dual-Fuel Combustion and Prechamber Model

Page 19 of 22 
for Large Two-Stroke Engines within a Fast 0D / 1DSimulation Environment”, 2019.

[26] Wenig, M., Fogla, N., \& Roggendorf, K., "Towards Predictive Dual-Fuel Combustion and Pre-Chamber Modeling for Large Two-Stroke Engines in the Scope of 0D/1D Simulation", 2019.

[27] Olsen, D.B., \& Lisowski, J.M., "Prechamber NOx formation in low BMEP 2-stroke cycle natural gas engines", Applied Thermal Engineering. 29(4):687-694, 2009, doi:10.1016/j.applthermaleng.2008.03.049.

[28] Onofrio, G., Li, C., Garcia Valladolid, P., De La Morena, J. et al., "Experimental and Numerical Assessment of Active Pre-chamber Ignition in Heavy Duty Natural Gas Stationary Engine," SAE Technical Paper 2020-01-0819, 2020, doi: $10.4271 / 2020-01-0819$.

[29] Biswas, S., Tanvir, S., Wang, H., \& Qiao, L., "On ignition mechanisms of premixed CH4/air and H2/air using a hot turbulent jet generated by pre-chamber combustion", Applied Thermal Engineering. 106(5):925-937, 2016, doi:10.1016/j.applthermaleng.2016.06.070.

[30] Tang, Q., Sampath, R., Echeverri Marquez, M., Hlaing, P. et al., "Simultaneous Negative PLIF and $\mathrm{OH}^{*}$

Chemiluminescence Imaging of the Gas Exchange and Flame Jet from a Narrow Throat Pre-Chamber," SAE Technical Paper 2020-01-2080, 2020, doi:10.4271/202001-2080.

[31] Malé, Q., Staffelbach, G., Vermorel, O., Misdariis, A. et al., "Large Eddy Simulation of Pre-Chamber Ignition in an Internal Combustion Engine," Flow, Turbulence and Combustion. 103:465-483, 2019, doi:10.1007/s10494019-00026-y.

\section{Contact Information}

\section{Ponnya Hlaing}

Ph.D. Student

Clean Combustion Research Center (CCRC)

Internal Combustion Engine Lab

King Abdullah University of Science and Technology (KAUST)

Thuwal, Saudi Arabia

ponnya.hlaing@kaust.edu.sa

Phone no: +966 565485657

\section{Acknowledgments}

The paper is based upon the work supported by Saudi Aramco Research and Development Center FUELCOM3 program under Master Research Agreement Number 6600024505/01. FUELCOM (Fuel Combustion for Advanced Engines) is a collaborative research undertaking between Saudi Aramco and KAUST intended to address the fundamental aspects of hydrocarbon fuel combustion in engines, and develop fuel/engine design tools suitable for advanced combustion modes

The authors would like to thank King Abdullah University of Science and Technology (KAUST) and the Clean Combustion Research Center (CCRC) for lab facilities and research support. Finally, the authors would like to convey gratitude towards the IC Engine Lab Safety Supervisor Adrian I. Ichim and the lab technician Riyad H. Jambi for their kind input and assistance in performing the experiments. The authors would like to express gratitude towards
The Lee Company for providing the details and specifications of the check valve used in the pre-chamber studies.

\section{Abbreviations}

$A_{T}$

CA10

CA90

CAD aTDC

$C_{d}$

FuelMEP

$\boldsymbol{h}$

IMEPg

$\lambda$

Lub. Oil

m

MC

$\boldsymbol{P}$

PC

PCC

ppm

$Q_{L H V}$

QMEP

ROHR

SI

$T$

V

$\gamma$

$\boldsymbol{\theta}$
Total area of nozzle holes

Crank angle at $10 \%$ of cumulative heat release

Crank angle at $90 \%$ of cumulative heat release

Crank angle degree after top-deadcenter

Discharge coefficient through the pre-chamber

Fuel mean effective pressure

Enthalpy transfer between PC and MC

Gross indicated mean effective pressure

Excess air ratio

Lubricating oil

Mass transferred between the prechamber and the main chamber

Main chamber

Pressure

Pre-chamber

Pre-chamber combustion

Parts per million

Lower heating value

Heat mean effective pressure

Rate of heat release

Spark ignition

Temperature

Volume

Specific heat ratio

Crank angle degree 
Appendix A: Main chamber pressure for a single cycle with highest knock intensity for each fuel

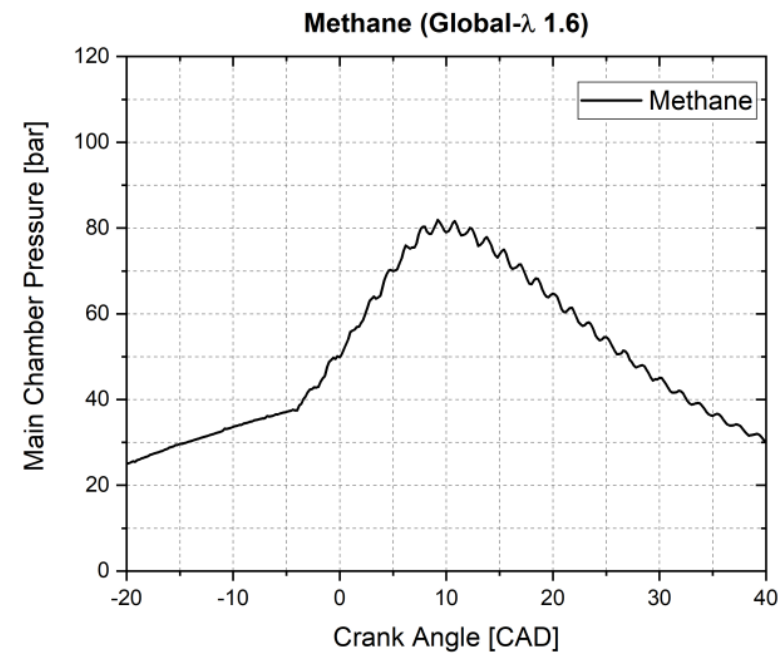

(a)

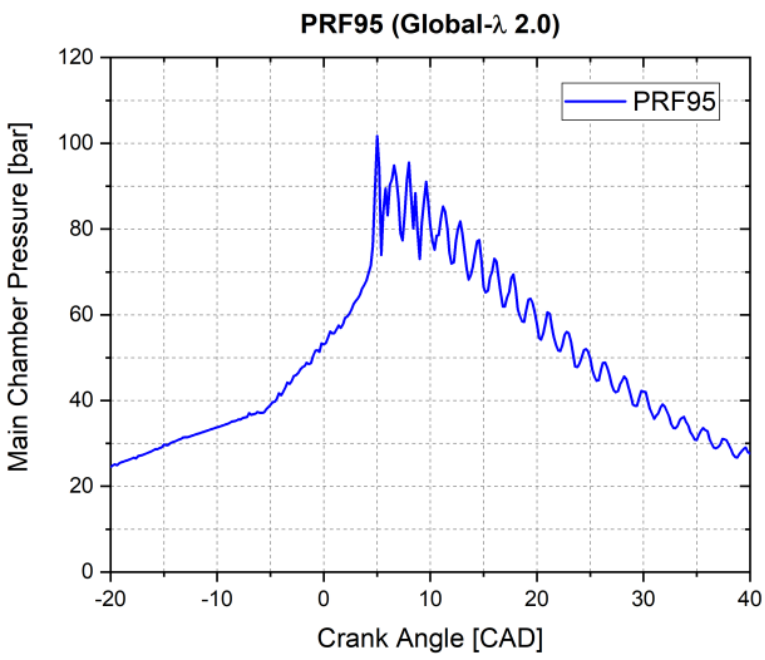

(c)

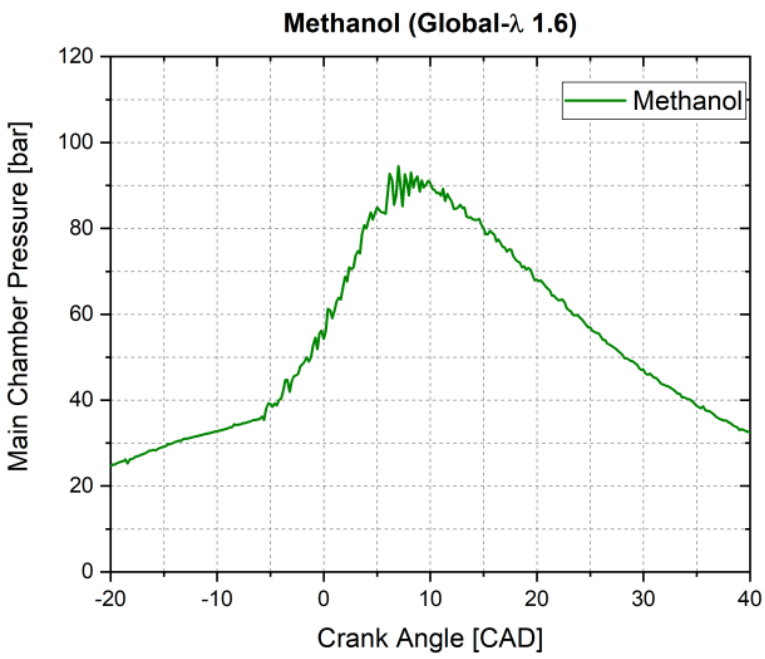

(e)

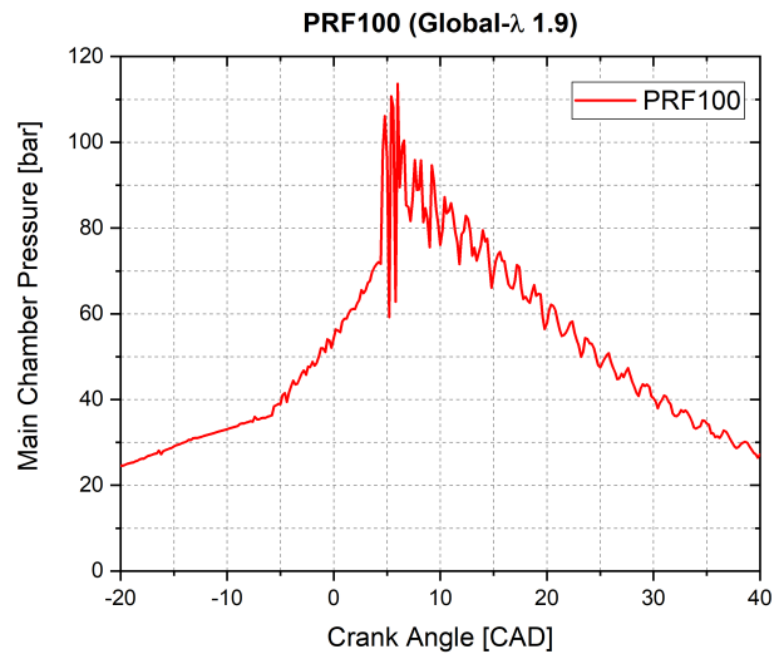

(b)

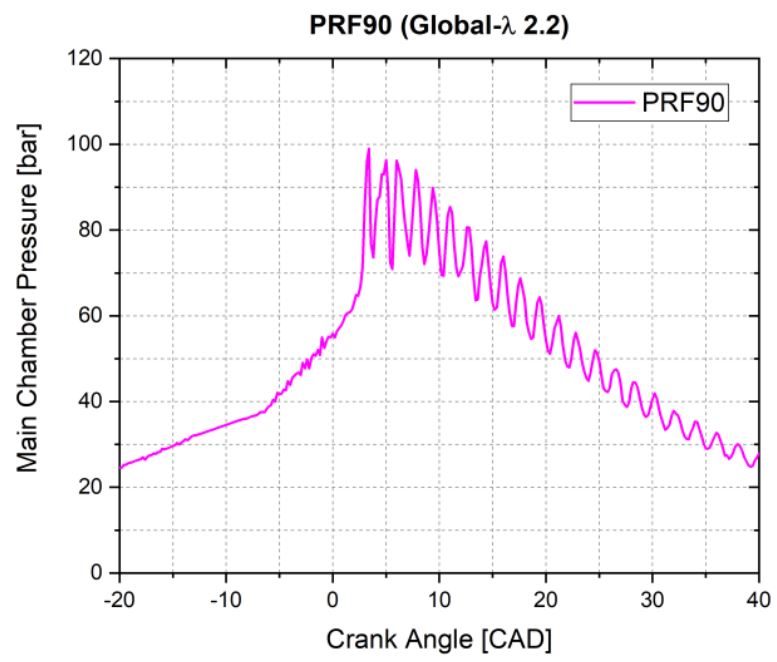

(d)

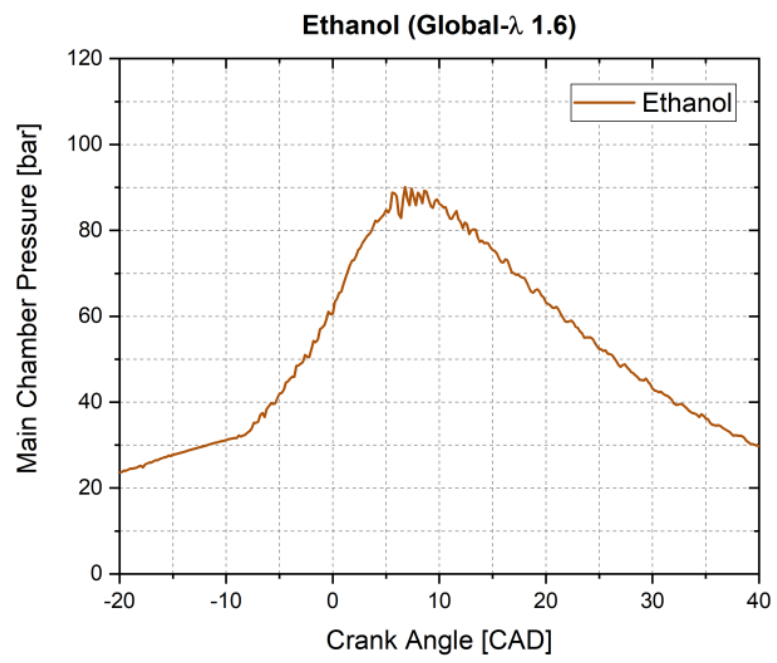

(f)

Figure A.1 - Main chamber pressure of a single cycle with the highest knock intensity: (a) Methane, (b) PRF100, (c) PRF95, (d) PRF90, (e) Methanol and (f) ethanol

Page 21 of 22

$01 / 28 / 2020$ 
Appendix B: Effect of spark timing on specific NOx emission at the ultra-lean conditions for PRF Fuels

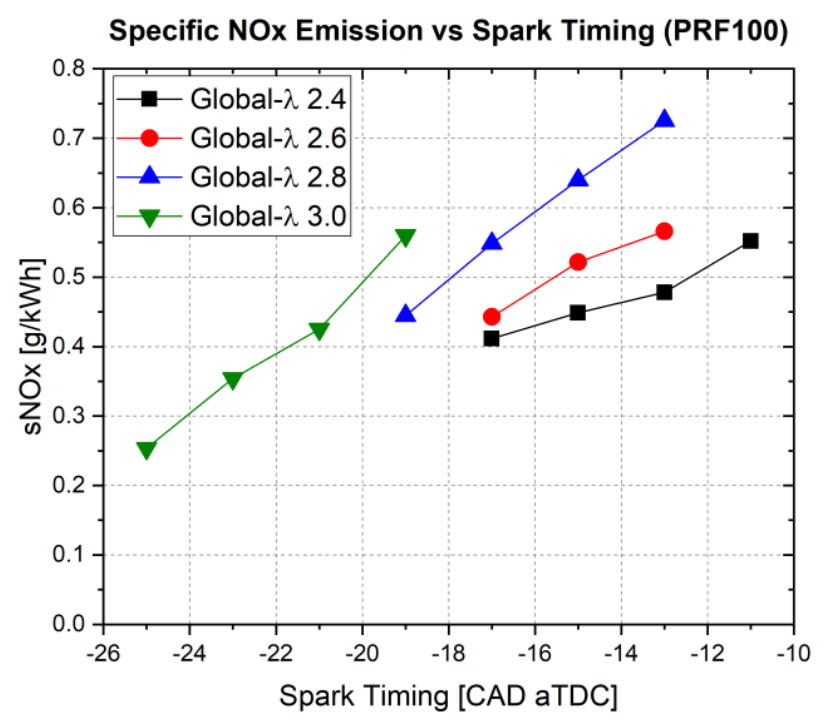

(a)

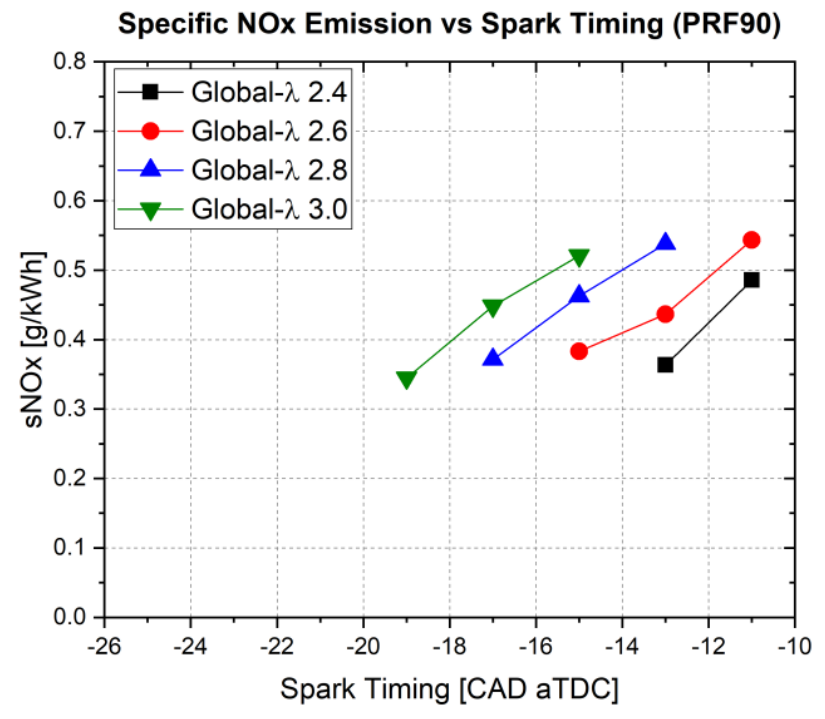

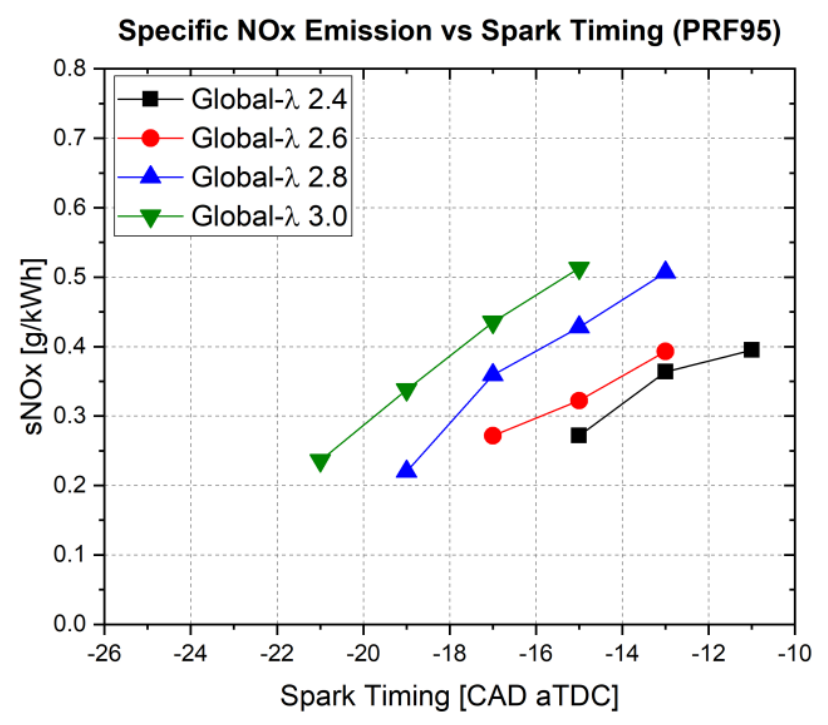

(b)

(c) 